\title{
Methodology and Findings of the NRC's Materials Licensing Process Redesign
}

Manuscript Completed: April 1996

Date Published: April 1996

P. A. Rathbun, K. D. Brown, J. R. Madera, M. Moriarty,

J. M. Pelchat, W. K. Usilton, J. E. Whitten, P. C. Vacca

Division of Industrial and Medical Nuclear Safety Office of Nuclear Material Safety and Safeguards U.S. Nuclear Regulatory Commission

Washington, DC 20555-0001

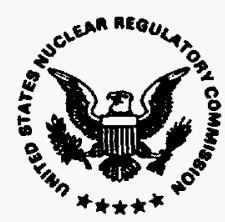




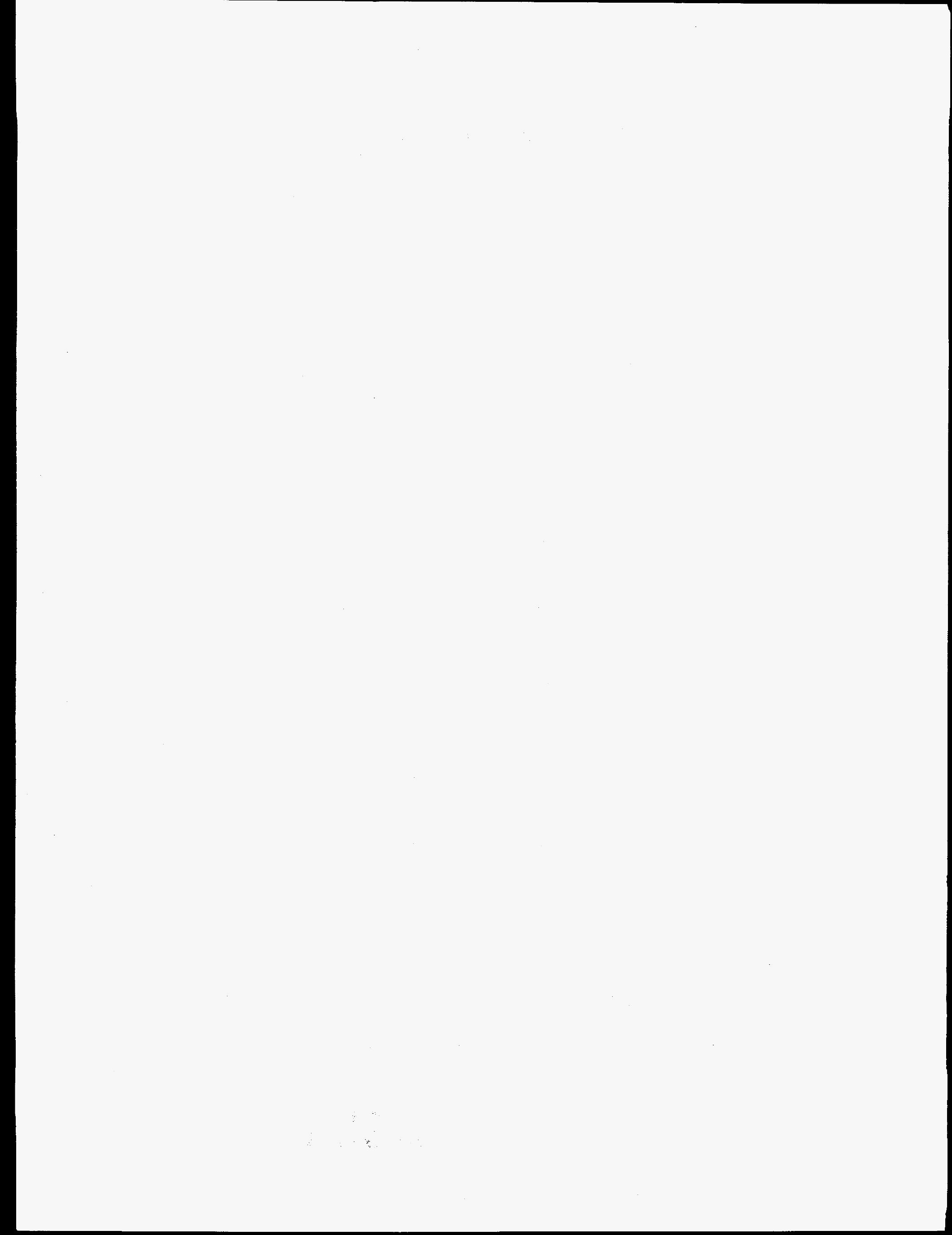




\section{ABSTRACT}

This report describes the work and vision of the team chartered to redesign the process for licensing users of nuclear materials. The Business Process Redesign team was chartered to improve the speed of the existing licensing process while maintaining or improving public safety and to achieve required resource levels. The report describes the team's methods for acquiring and analyzing information about the existing materials licensing process and the steps necessary to radically change this process to the envisioned future process. 



\section{DISCLAMMER}

Portions of this document may be illegible in electronic image products. Images are produced from the best available original document. 


\section{Table of Contents}

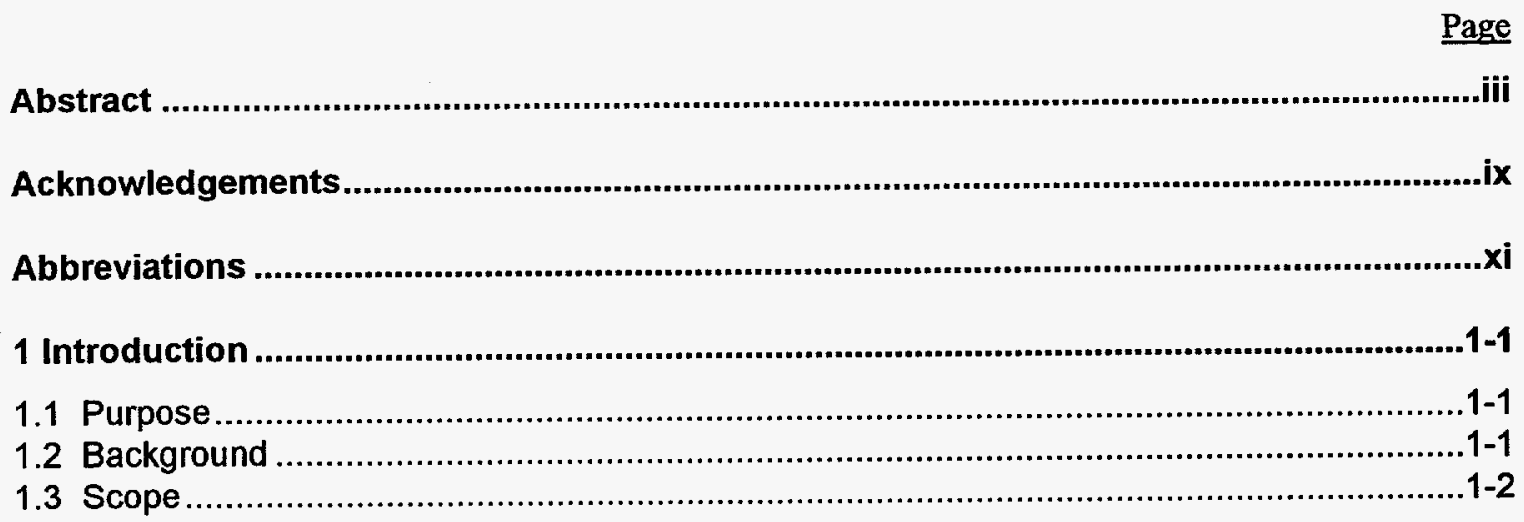

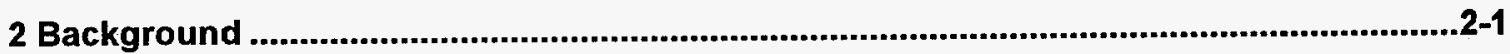

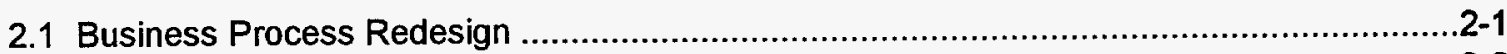

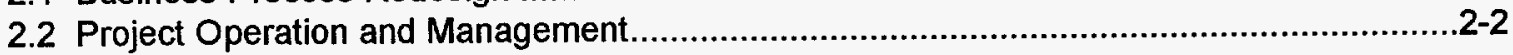

3 Required Elements for Large-Scale Change..................................................................3-1

3.1 Overcoming Inertia ................................................................................................

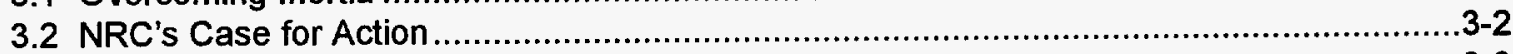

3.3 Collection of NMSS Licensing Process Data .................................................................

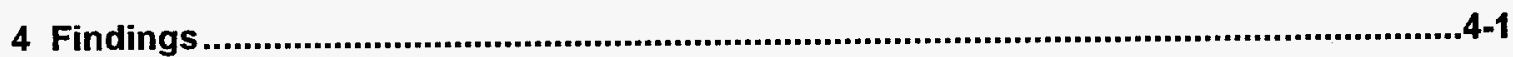

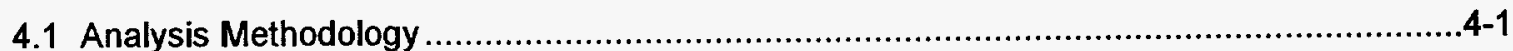

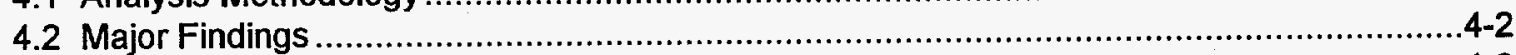

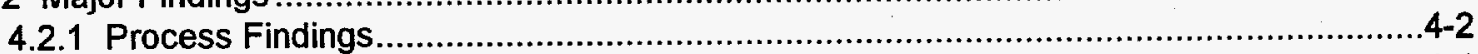

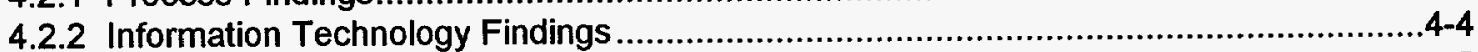

4.2.3 Jobs, Skills, and Organization Findings ..............................................................

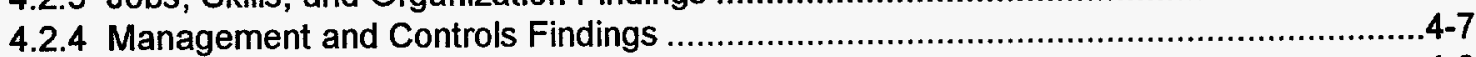

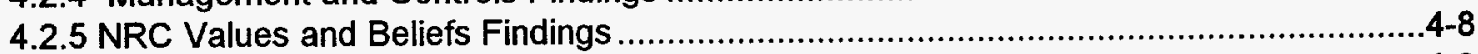

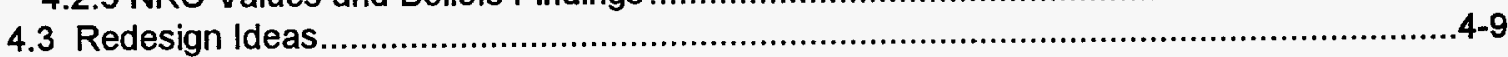

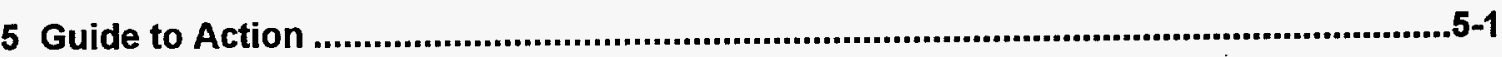

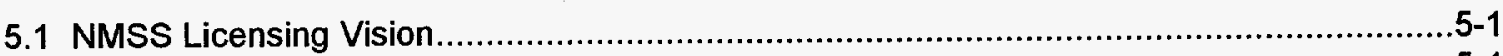

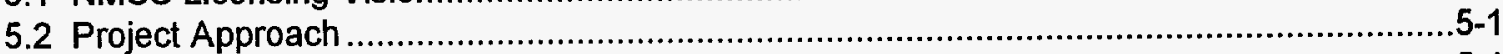

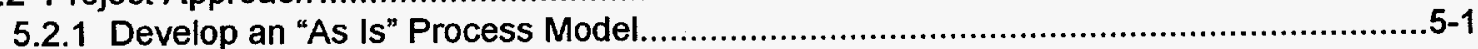

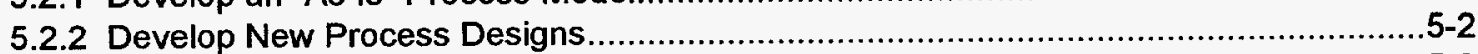

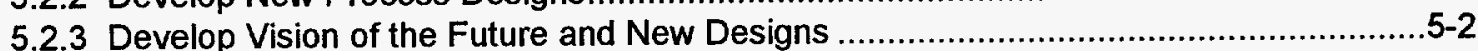

5.2.4 Management Presentation............................................................................... $5-2$

6 Baselining the Process ...............................................................................................6-1

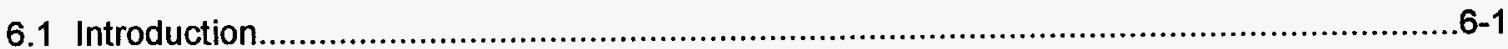

6.1.1 Licensee satisfaction with NRC licensing system service ........................................6-1

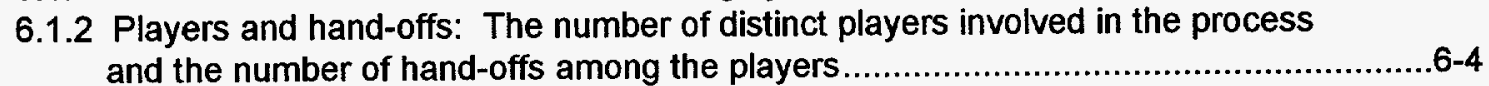

6.1.3 Processing time: Total work time required to complete each step ...........................6-6

6.1.4 Cycle time: Total elapsed time required to complete each step................................6-6

6.1.5 Accessibility of Information ...............................................................................6-6

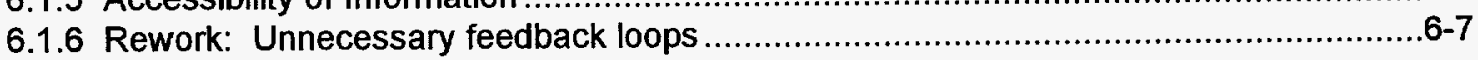




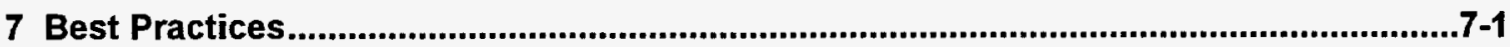

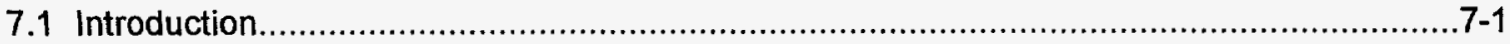

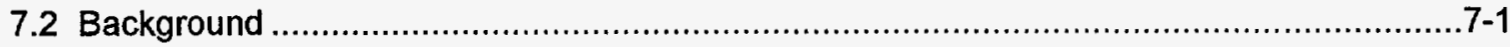

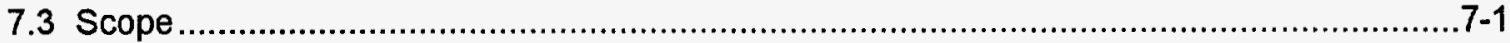

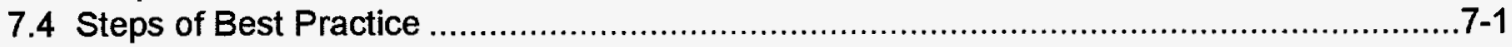

7.4.1 Determine Best Practice Categories ................................................................. $7-1$

7.4.2 Research Best Practice Articles ...................................................................... $7-2$

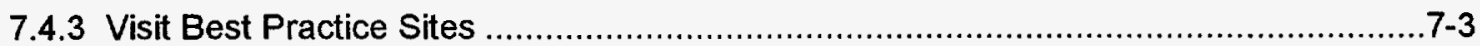

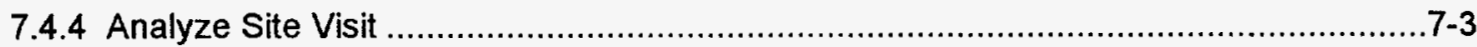

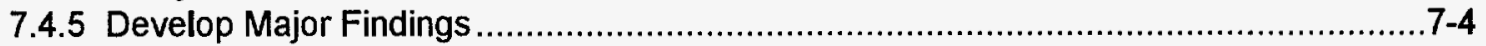

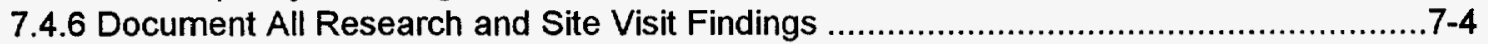

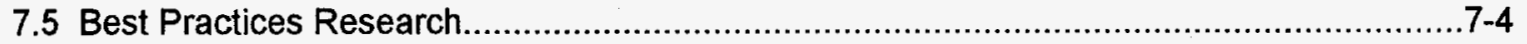

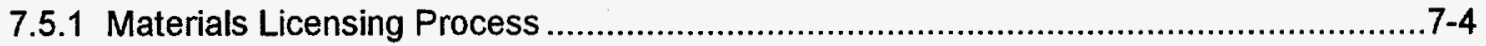

7.5.2 Information Technology: Client/Server Infrastructure ............................................ 7-7

7.5.3 Jobs, Skills, and Organization .......................................................................

7.5.4 Management and Controls: Change Management and Leadership ............................ $7-9$

7.5.5 Values and Beliefs: Customer Service ........................................................... $7-10$

7.5.6 Regulatory Product Development ............................................................

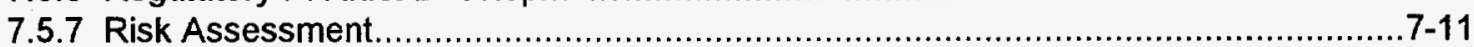

8 Vision of the Future Materials Licensing Process........................................................

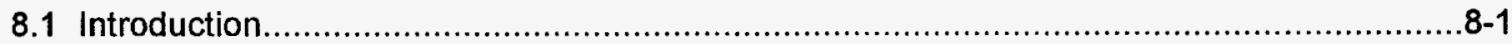

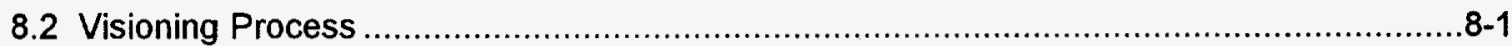

8.3 Business Diamond Area Requirements and Potential Impacts ...................................8-7

8.3.1 Major Process Requirements and Potential Impacts .........................................8-7

8.3.2 Information and Technology Requirements and Potential Impacts ...........................8-8

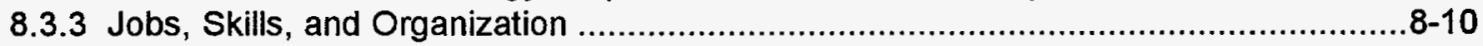

8.3.4 Management and Control Requirements and Impacts.......................................8-11

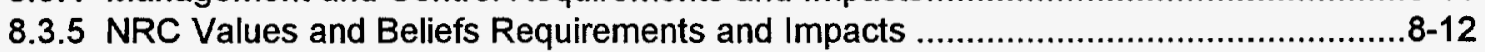

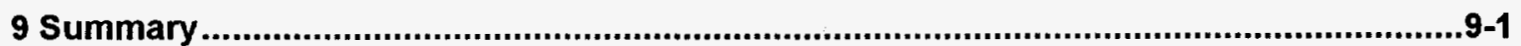




\section{Appendices}
A Materials Licensing BPR Core Team Project Charter
B Conceptual Picture of the Current Materials Licensing Process
C Actual NMSS Materials Licensing Process
D Current Technical Assistance Request Process

\section{Tables}

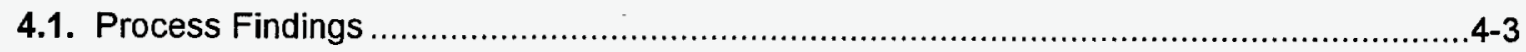

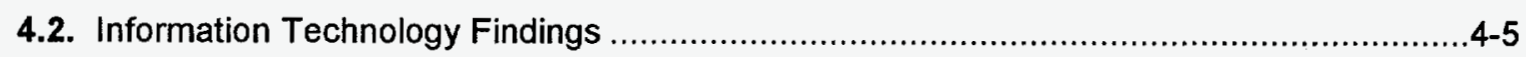

4.3 Jobs, Skills, and Organization Findings .............................................................. $4-6$

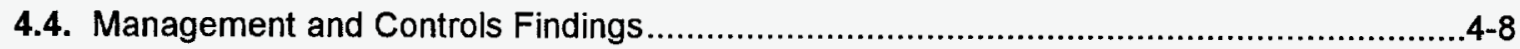

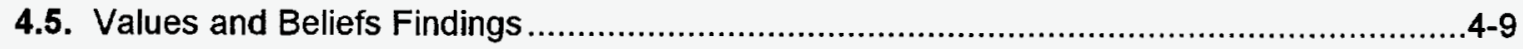

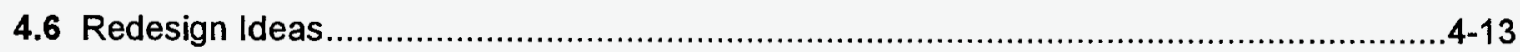

7.1 Best Practice Sites and Key Area of Focus .........................................................

7.3 Site Visit Relevance to Best Practice Categories .......................................................

\section{Figures}

2.1 Management Model for NMSS Materials Licensing BPR Project ..................................2-3

3.1. Three Elements Required for Rapid Organization Change ............................................2

3.2 NRC's Materials Licensing Case for Action ................................................................

3.3 NMSS Materials Licensing BPR Team Data Collection Process ......................................5

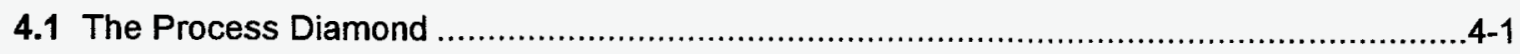

6.1 Players and Hand-offs in Step 1 of the Former Materials Licensing Process ....................6-5

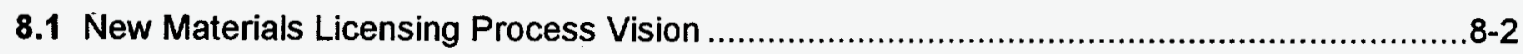


CONTENTS

Figures (continued)

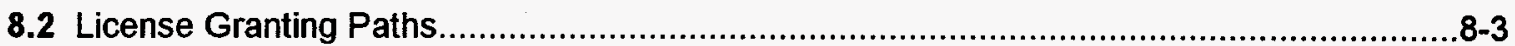

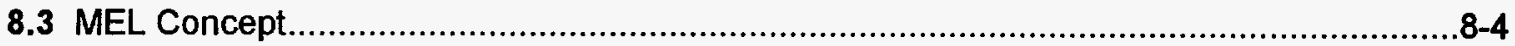

8.4 Accelerated Regulatory Product Set Development ....................................................

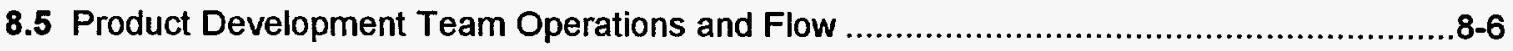




\section{Acknowledgment}

The Business Process Redesign (BPR) team thanks the individuals listed on the next page for participating in the data collection phase of the Nuclear Materials Safety and Safeguards (NMSS) materials licensing BPR project. All of these participants provided valuable insights and candid observations about the current materials licensing process and the diverse environments in which the process must operate.

In addition, the team thanks Dr. Carl J. Paperiello, Dr. Donald A. Cool, and Mr. Frederick C. Combs for their valuable technical comments, as well as for providing the management support required for success in this endeavor.

Finally, the team thanks Veronica M. Bellone, David Greenwald, Karl Leatham, Alyce J. Martin, and Pamela Miller from Computer Sciences Corporation for their major contributions to the production of this document. 


\section{The Participants}

NRC Headquarters
Bangert, Richard
Bernero, Robert
Bird, Paul
Brach, E.W.
Bradford, Jay
Combs, Fred
Cranford, Gerald
Cyr, Karen
Dandois, Diane
Funches, Jesse
Glenn, John
Howe, Donna-Beth
Jackson, Glenda
Levin, Moe
Lohaus, Paul
Moriarty, Maureen
Olmstead, Bill
Pangburn, Greorge
Paperiello, Carl
Schneider, Kathy
Scroggins, Ronald
Smith, Phyllis
Vacca, Patricia
Weiss, Doug

\section{Region I}

Brown, Keith

Bellamy, Ron

Brown, Rebecca

Costello, Frank

Gross, Bob

Hehl, Bill

Henderson, Pam

Kane, William

Kinneman, John

Lee, Kim

Martin, Thomas

Martinson, Paul

McGrath, John

O'Daniell, Cindy
Perkins, Mike

Shankman, Susan

Villar, Sheryl

Ullrich, Betsy

\section{Region II}

Ennis, Jerry

Fuller, Mike

Heim, Diane

Henson, Jay

Hosey, Chuck

Mallet, Bruce

Pelchat, John

Potter, John

Reyes, Luis

Stohr, J. P.

Whitt, Nancy

Wright, Earl G.

\section{Region III}

Ariano, Carol

Axelson, William

Caniano, Roy

Casey, Colleen Carol

Grobe, Jack

Holt, B. J.

Hueter, Loren J.

Kerlin, Martin

Lynn, Linda

Madera, John

Martin, John B.

McCann, George (Mike)

Meenan, Marianne

Miller, H.J.

Mullauer, James

Pelke, Patricia

Piskura, Deborah A.

Vacherlon, Patricia

Watson, Gidget

\section{Region IV}

Arlington Office and

Walnut Creek Field Office

Bacon, Debby

Brown, Bob

Burks, Jackie

Callan, L.J.

Campbell, Vivian

Chaney, Dean

Fisher, Bill

Garcia, Joan Q.

Gruszynski, Billie

Hernandez, Christi

Howell, Linda

Montgomery, James L.

Montgomery, John M.

Phillips, Michael

Prange, Beth A.

Rettig, Jayallen

Scarano, Ross

Shaffer, Mark

Talbot, Jody

Whitten, Jack 


\section{Abbreviations}

ACMUI Advisory Committee on the Medical Uses of Isotopes

AEOD

Office for Analysis and Evaluation of Operational Data

AS

Agreement State

BPR

Business Process Redesign

CFA

Case for action

COTS

Commercial, Off-the Shelf

DTP

Desk top publishing

EDO

Office of the Executive Director for Operations

FY

Fiscal Year

GUI

Graphical User Interface

IRM

Office of Information Resources Management

IT

Information Technology

JSO

Jobs, Skills, and Organization

LANs

Local Area Networks

LTS

License Tracking System

MEL

Materials Electronic Library

MHO

Maximum Number of Hand-offs

NMSS

Nuclear Materials Safety and Safeguards

NRC

Nuclear Regulatory Commission

NUDOCS Nuclear Document System

$\mathrm{OC}$

Office of the Controller

OGC

Office of the General Counsel

OSP

Office of State Programs 


\section{Abbreviations (continued)}

RDI Review Downtime Index

RGN-1 Region I

RGN-2 Region II

RGN-3 Region III

RGN-4 Region IV

RHO Routine Number of Hand-offs

RITS Regulatory Information Tracking System

SMWT(s) Self-managed Work Team(s)

TAR(s) Technical Assistance Request(s)

TTC Technical Training Center

WANs Wide Area Networks

WCFO Walnut Creek Field Office 


\section{Introduction}

\subsection{Purpose}

This document describes the methodology and approach taken by the United States Nuclear Regulatory Commission (NRC) staff to fundamentally redesign the current materials licensing process.

\subsection{Background}

The project's objectives were established by the NRC Office of Nuclear Materials Safety and Safeguards (NMSS), the project's originator. The Business Process Redesign (BPR) team's charter (Appendix A) was approved by the NRC Office of the Executive Director for Operations (EDO).

The project's initial objectives were as follows:

Conduct an analysis of the materials licensing process workflow to determine how the NRC processes an application from receipt to issuance. The long-term goal is to establish more efficient and potentially automated processing of material license and amendment requests. The project will determine ways to streamline, automate, and avoid duplication of effort in processing the license request, provide cost saving in resources in NRC's materials licensing process, and improve communication with materials licensees.

After the initial objectives and BPR management model were established, very specific goals for the project and directions to the redesign BPR core team were defined. In brief, these goals were to examine NRC's current materials licensing process and develop a new materials licensing process design that-

- maintains or raises the current level of public safety,

- improves the overall speed of the licensing process by an order of magnitude,

- exploits modern information technology as a fundamental part of the new process, and

- reduces resources to meet 1998-1999 staffing levels. 
The core team was directed to-

- examine all related and supporting processes,

- look outside NRC for best practices and ideas,

- determine licensee readiness for change and consider licensee-provided redesign ideas to meet licensees' present and future requirements,

- use the charter's governance model to report issues and recommendations,

- be available full time during periods when the BPR core team meets,

- present early high-payoff changes that can be implemented, and

- present a new NMSS licensing process that can be implemented.

The NRC established a charter goal of an order of magnitude improvement in materials licensing speed and efficiency. This aggressive goal necessarily required the BPR team to examine and challenge all assumptions that underlie both the current process and the closely related processes that have an impact on materials licensing timeliness and efficiency.

The end product of the team's efforts is a proposed new materials license process design that can be approved by NRC's senior management and substantially implemented within a relatively short period.

\subsection{Scope}

The remainder of this report is organized as follows: Section 2 describes the background for this project; Section 3 describes BPR in the context of the NRC's materials licensing process; Section 4 presents the BPR team's data collection methodology and findings; and Section 5 then describes the steps that the core team followed to derive a new materials licensing process vision. Section 6 presents the baseline metrics for measuring the performance of both the current and future NMSS licensing process. Section 7 describes the "best practices" approach and results obtained by the core team. Section 8 presents the new licensing process vision defined by the team. 


\section{Background}

\subsection{Business Process Redesign}

The NMSS licensing project used a BPR methodological approach to making largescale change. To improve process efficiency and effectiveness, BPR applies principles of change management to core processes.

\section{What is BPR?}

BPR is a methodology for accomplishing rapid, large-scale, fundamental changes to core processes. Specifically, BPR is defined to be-

- the concept of fundamentally changing the way work is performed in order to achieve radical performance improvements in speed, cost, and quality; and

- the process of making a "big change-fast."

Several parts of the definition are key to understanding BPR. First, BPR seeks to make fundamental changes to core business processes. Second, BPR seeks radical, not incremental, performance improvements in speed, cost, and quality. Finally, BPR implements a big change-fast - to core processes.

\section{What are the principles involved in BPR?}

The team used well-proven BPR principles, especially the following:

- examining the licensing process from both an outside and cross-functional point of view,

- setting ambitious goals for the redesign,

- challenging old beliefs and old ways of performing the licensing process, and

- exploiting an innovative thinking approach that focuses on the outcomes to be achieved.

\section{What are the BPR goals?}

The BPR team targeted an order of magnitude improvement in licensing process speed, efficiency, and quality. Achieving this very aggressive goal required the BPR team to develop and recommend fundamental, rapid, and large-scale changes to the way materials licensing work is performed. 


\section{How will it be done?}

Successful BPR efforts require continuous change management to move the affected organization along a redesign journey.

The BPR team defined the following specific changes required to support the new NMSS licensing process:

- new uses of information technology,

- redesigned jobs and skills,

- new management and controls, and

- changes to licensing staff values and beliefs.

A key part of the redesigned licensing process is a set of performance measures that report performance of the new process in real time. Early in the redesign effort, the BPR team agreed upon and reported to the Steering and Executive Committees, what these measures were and why it is important to track license process performance in terms of speed, quality, customer satisfaction, and public health and safety. These agreed-upon measures formed the basis for more detailed process subdesigns that would occur in the prototyping stage of process implementation and would ensure that the new process, when fully implemented, would meet performance expectations.

\section{How was management involved?}

The BPR approach realized a large measure of its success owing to the use of a strong management model that involved senior NRC management in all key decisions regarding the BPR. The next section describes that model.

\subsection{Project Operation and Management}

The NMSS licensing BPR project was organized into three levels: core team, steering committee, and executive committee. Each level had a key role in the overall project operation and management.

The licensing BPR project management model in Figure 2.1 shows the relationships between each of the three levels. The core team made use of its own cross-functional makeup and outside expertise to perform its primary role of defining a new materials licensing process. The core team reported issues as they occurred and reported team results to the steering committee. Similarly, the steering committee reported issues as they occurred and reported major core team results to the executive committee at key milestones. Roles and makeup of each group are described below. 


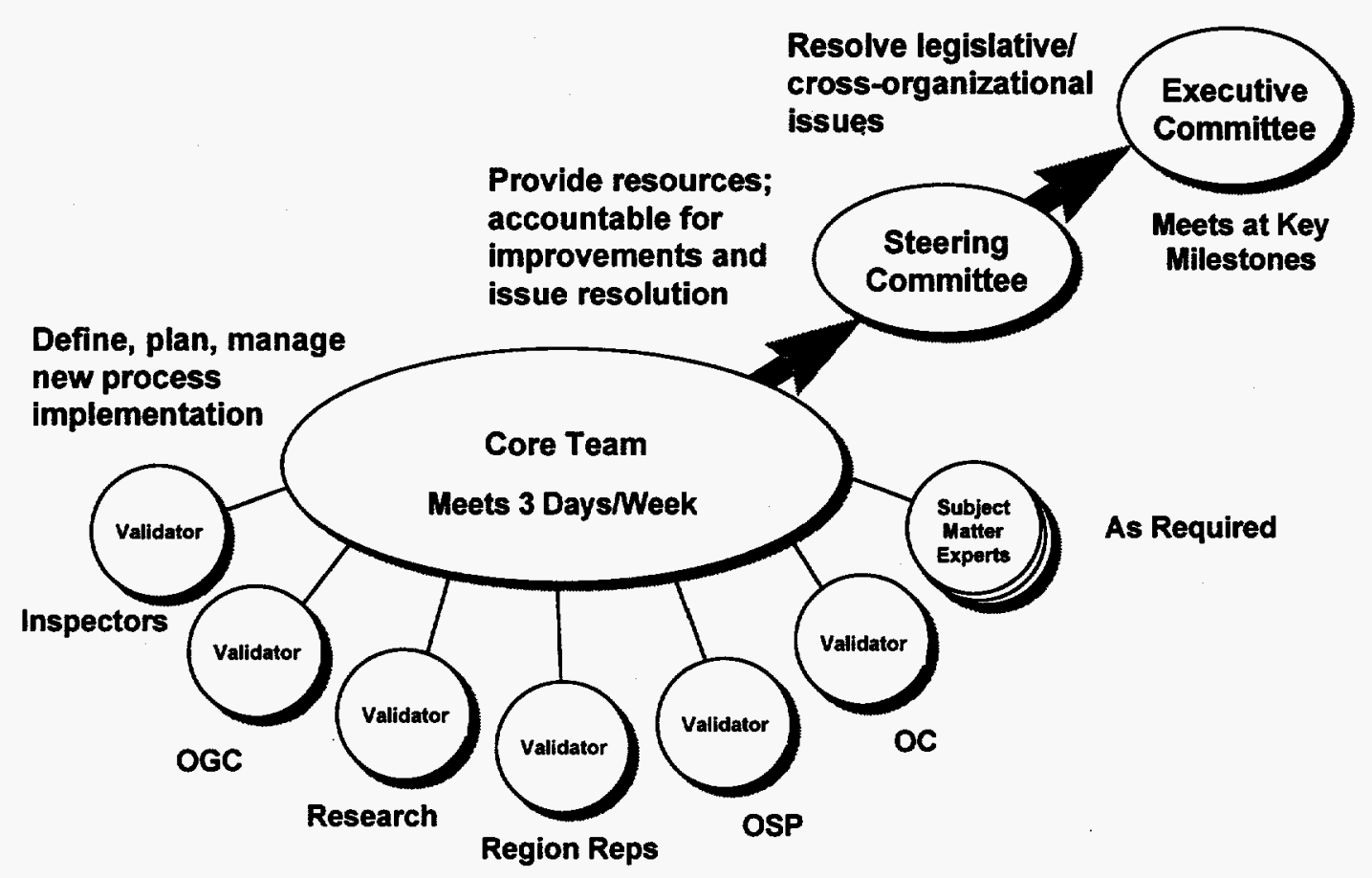

Figure 2.1 Management Model for NMSS Materials Licensing BPR Project. The steering and executive committees provide effective management oversight of the NMSS $B P R$ project.

\section{Executive Committee}

The BPR executive committee represented the agency stakeholders and provided executive oversight of the materials licensing process. The executive committee provided agencywide management and integration of cross-organizational issues, a channel for policy and legislative issues, and mediation of unresolved turf issues and disagreements. Although there have been changes to the Executive Committee, the original members are listed below. 
Members:

$\begin{array}{llll}\text { EDO } & \text { Hugh L. Thompson, Jr. (Chair) } & \text { AEOD } & \text { Edward L. Jordan } \\ \text { NMSS } & \text { Robert Bernero } & \text { RGN-1 } & \text { Thomas T. Martin } \\ \text { IRM } & \text { Gerald F. Cranford } & \text { RGN-2 } & \text { Stewart D. Ebneter } \\ \text { OC } & \text { Ronald M. Scroggins } & \text { RGN-3 } & \text { John B. Martin } \\ \text { OGC } & \text { William J. Olmstead } & \text { RGN-4 } & \text { Leonard Joe Callan }\end{array}$

OSP Richard L. Bangart

\section{Executive Committee Reporting:}

The BPR Steering Committee Chair, assisted by designated core team members, reported the completion and results of key milestones and issues to the BPR Executive Committee and reported executive committee-level issues as they occurred.

\section{Steering Committee}

The BPR Steering Committee represented and supported the people responsible for managing and overseeing the materials licensing and related processes. The steering committee's resolution of issues identified by the BPR team demonstrated NMSS's visible ownership of and commitment to the BPR team's efforts. Other important roles included accepting accountability for improving the licensing process and related processes and selecting, supporting, and providing resources for the BPR core team. Although there have been changes to the Steering Committee, the original members are listed below.

\section{Members:}

NMSS Carl J. Paperiello (Chair)

E. William Brach

Margaret V. Federline

Frederick C. Combs

IRM Charles E. Fitzgerald

OC Jesse L. Funches

OSP Paul H. Lohaus
EDO Lynn B. Scattolini/ Newton (King) Stablein

RGN-1 Susan F. Shankman

RGN-2 Bruce S. Mallett

RGN-3 William L. Axelson

RGN-4 Samuel J. Collins

\section{Steering Committee Reporting:}

The core team reported results to the steering committee and reported issues as they occurred. 


\section{Core Team}

The BPR core team represented the facilitators of the effort to redesign the materials licensing process. The BPR core team defined, planned, managed, and executed the BPR. Responsibilities included meeting the EDO's charter for licensing process improvement goals, exploiting specialized NRC staff skills during new process development, and providing team results to the steering and executive committees as required by the management model. Although there have been changes to the core team, the original members are listed below.

\section{Members:}

NMSS Patricia A. Rathbun (Team Leader) Maureen Moriarty

Patricia C. Vacca

IRM William K. Usilton

\author{
RGN-1 Keith D. Brown \\ RGN-2 John M. Pelchat \\ RGN-3 John R. Madera \\ RGN-4 Jack E. Whitten
}

\section{Subject Matter Adjunct Members:}

OC Shelly L. Creed/Glenda C. Jackson

OSP Kathleen Schneider

\section{Issue Resolution}

Often, the core team presented issues to both the executive and steering committees for resolution. As these issues arose, the NRC BPR Team Leader reported them to the steering committee. Because the core team's schedule was very compressed, issues had to be resolved rapidly and proactively. The baseline rule was that-

Issues raised to the steering committee will be resolved within 48 hours or will be elevated by the steering committee chair to the executive committee. Similarly, the executive committee will have 48 hours following notification of an issue to give guidance on how the issue is to be resolved. 



\section{Required Elements for Large-Scale Change}

\subsection{Overcoming Inertia}

Organizations that successfully undertake and complete large-scale change must have a compelling case for action, a willingness to face the truth about the present, and a powerful vision of where they want their organization to be in the future.

\section{The inertia factor}

Organizations and the people who work in them, unless conditioned otherwise, normally resist rapid change-particularly large-scale change. Organizations are intended to achieve stability over time. This long-term stability allows an organization to establish core processes that achieve its purpose and to create implementing procedures.

Such is the case at NRC with the agency's mandate to protect public health and safety with stable, effective controls on radioactive materials. The existing licensing process developed to comply with that mandate and its effective, but not necessarily efficient, procedures are well-established and do, in fact, protect public health and safety.

Operational "habitforce," vested interests, culture, and risk aversion can all powerfully inhibit needed change. These forces that oppose change remain in effect until other, more powerful forces act on them, as shown in Figure 3.1.

\section{How can inertia be overcome?}

Large-scale changes are never accidental. BPR creates them systematically, first by demonstrating to members of the affected organization that they can no longer stay where they are ("Have a Compelling Case for Action") and, then that they must face the fact that today's process no longer serves the organization and must be scrapped ("Tell the Truth About Today"). These first two mindset changes combine to both "loosen" the forces holding the organization in place and "lever" it in the direction of change.

The third change is achieved by the "pull" created by a new and powerful vision of the future.

Only when these three required elements are in place could NRC's licensing community be induced to move rapidly to a new and better licensing process. 
1. Have a Compelling Case for Action

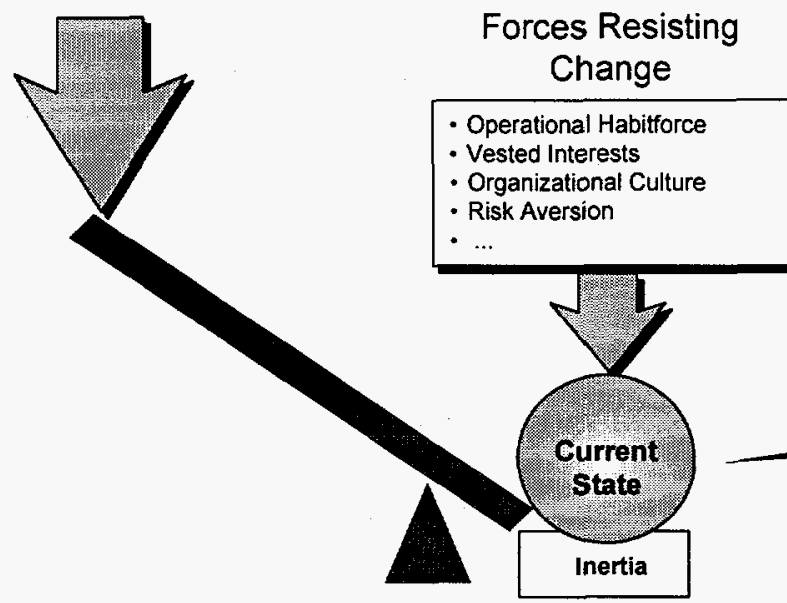

Forces Resisting

\section{Tell the Truth About Today}
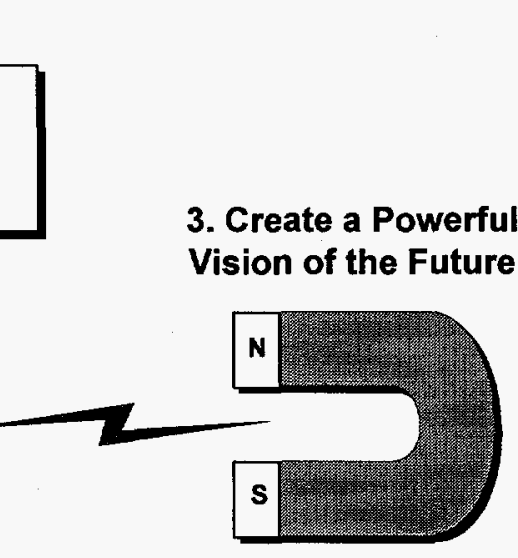

Figure 3.1. Three Elements Required for Rapid Organization Change. A compelling case for action and a powerful vision of the future can combine to quickly move an organization to a fundamentally new state, but only when the organization is willing to admit that the old way of doing business no longer works.

Section 3.2 presents the NRC materials licensing case for action as initially defined. Section 3.3 then discusses how the BPR team collected data to objectively assess the current state of the materials licensing process.

\subsection{NRC's Case for Action}

NRC's case for action (CFA) was driven by escalating fees and decreasing numbers of licenses. The CFA had its origins in the 100 -percent fee recovery rule mandated by Congress. NRC staff identified fees as a factor in the declining number of licensees that was first noted in 1989. Hard numbers on fee escalation and license decline, as depicted in Figure 3.2, presented a compelling case to dramatically change the licensing process. 


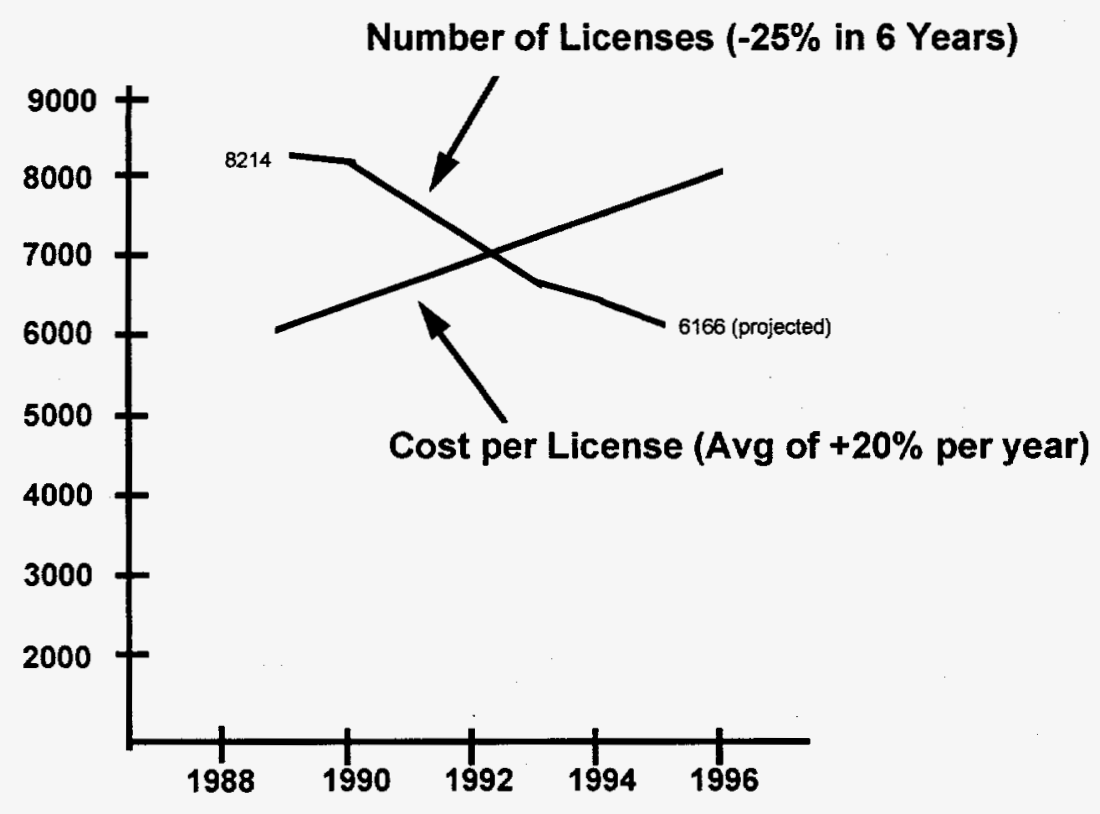

Figure 3.2 NRC's Materials Licensing Case for Action. By the end of 1996, if trends continue, the combined impact of a shrinking licensee base and rapidly escalating fees may place insupportable burdens on remaining licensees.

One manager stated that the average cost of an NRC-administered license has escalated at 20 percent per year. Meanwhile, the total number of active licenses has dropped dramatically, from 8,214 in September 1988 to 6,666 in September 1994. This is a decrease of about 19 percent. If Massachusetts becomes an Agreement State, it will further reduce the number of licenses NRC administers by about 500 , down to 6,166 . The 100-percent fee recovery rule would force these 6,166 licensees to bear the financial burden of the NMSS support organization required to administer licenses.

\subsection{Collection of NMSS Licensing Process Data}

To collect relevant data on the current licensing process from all significant stakeholder groups, the NMSS licensing BPR team used a defined data collection plan with tailored interview guides.

\section{How the data was collected}

The NMSS licensing BPR team collected data using the method shown in Figure 3.3. Initially, the NRC BPR Team Leader identified the significant stakeholder groups to be interviewed. These were divided into two principal groups-those who manage the licensing process and those who perform the process. A data collection plan was then developed to schedule and interview individuals within these groups. Interview guides were developed for interviewing individuals in each major stakeholder group. 
Sections 1 through 4 of this report are the end products of interviewing more than 80 NRC employees. The acknowledgments page at the beginning of this report lists these individuals by organizational location.

\section{Expansion of the original interview population}

As interviews proceeded, particularly in Regions I and II, it became apparent that the licensee populations differ in very important ways among regions and that information from each region was needed to have a balanced set of interview data. Visits were, therefore, scheduled in all regions to capture these regional differences. Within NRC headquarters, additional interviews were scheduled with the Office of State Programs to further clarify the Agreement State perspective.

Data collected from individual interviews was consolidated, and a content analysis was performed on the data to abstract the interview findings and consequences. This is presented in Section 4 of this report. The specific methodology used to perform the current state analysis is described in Section 4.1. 


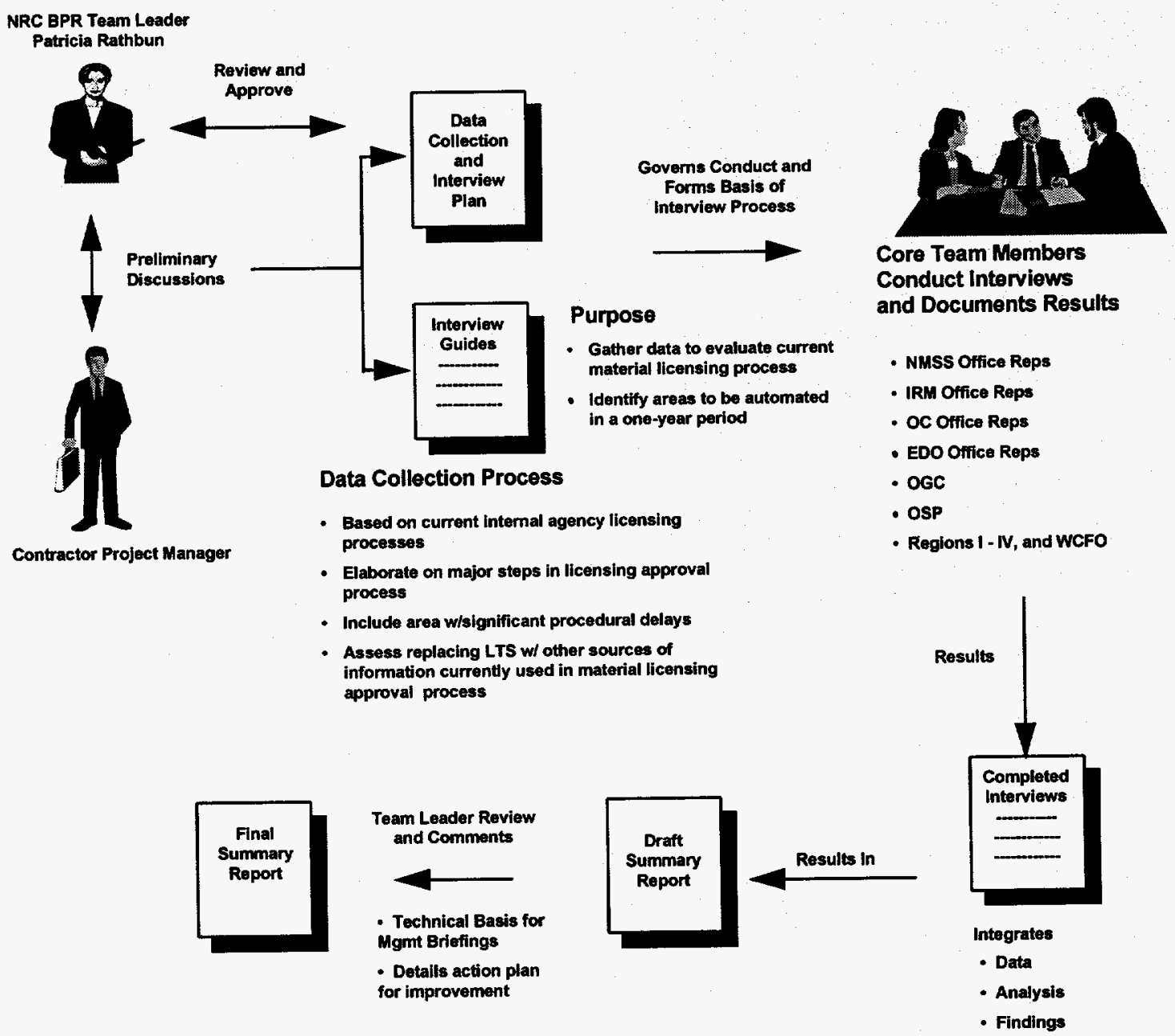

Figure 3.3 NMSS Materials Licensing BPR Team Data Collection Process. Members of the NRC core team and the contractor used the defined NMSS licensing data collection process to interview major licensing stakeholder groups and gain their perspectives. 



\section{$4 \quad$ Findings}

\subsection{Analysis Methodology}

The materials licensing BPR team used a three-step, comprehensive approach to develop a robust description of the current licensing process.

\section{The Process Diamond Approach}

The BPR team examined the materials licensing process from the viewpoint of the process diamond shown in Figure 4.1. The process diamond represents a useful framework to model various aspects of a given organization. A process consists both of its steps (see Appendix B) for a depiction of the current licensing process) and its supporting information technology; jobs, skills, and organization of the staff; management and controls; and the values and beliefs of the agency. Changing any part of the process diamond affects all other parts as indicated by the double headed arrows. Hence any major change, like the change that was contemplated for the NMSS licensing BPR project, would have major impacts in all areas of the process diamond.

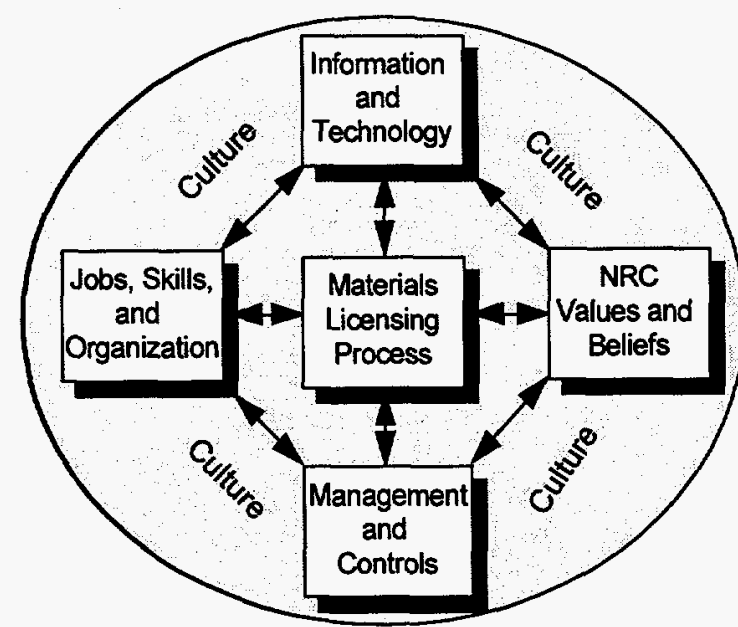

The process diamond provides an overall view of the total impact of change on an organization.

Figure 4.1 The Process Diamond. Changing any part of the process diamond affects all other parts. 


\section{Building the Model}

The findings, based on the process diamond shown in Figure 4.1, were developed from information about the current state of-

- the materials licensing process,

- Information Resources Management (IRM),

- human resources,

- NRC management systems and controls, and

- NRC values and beliefs.

In addition to analyzing "current state" information, the interviewers and the team sought information about redesign possibilities (i.e., ways to make the materials licensing process fundamentally effective and efficient, as well as responsive to current licensee needs). Interview guides were developed to assess each of these areas.

\section{Analysis}

BPR team members analyzed the interview responses by using content analysis procedures to categorize the data and relate it to the major topics of the process diamond.

\subsection{Major Findings}

The materials licensing BPR project data collection process identified 22 major findings that together comprehensively describe the current process.

\subsubsection{Process Findings}

The old process was characterized by an "apprenticeship" approach. It was generally "manual, individual, and subjective." A technical reviewer had full authority to issue or deny a license without his or her decision being subjected to formal group review. Such autonomy, coupled with regionalization, has led to some inconsistencies in license issuance.

Escalating fees, licensee confusion, and outdated standards were ranked next as staff concerns. Most, if not all interviewees, agreed that fees for materials licenses have skyrocketed in the last several years and made some licensees go out of business. The licensing process bewilders many licensees. In addition, because they resubmit their applications multiple times, licensees find outdated guidance a hindrance. 
Finding 1 - Standard core materials licensing processes are largely undefined at the organizational level and unsynchronized with Agreement States.

Finding 2 - Most interviewees perceive the escalating fee structure as unfair and unrealistic.

Finding 3 - Guidance is outdated, too general, and unconsolidated.

Finding 4 - Many licensees are bewildered by the process.

Finding 5 - Rulemaking is time consuming.

See Table 4.1 for the potential consequences of these findings.

Table 4.1. Process Findings

\begin{tabular}{|l|l|}
\hline \multicolumn{1}{|c|}{ Finding } & \multicolumn{1}{c|}{ Potential Consequence } \\
\hline $\begin{array}{l}\text { Standard core materials licensing processes } \\
\text { are largely undefined at the organizational } \\
\text { level and unsynchronized with Agreement } \\
\text { States. }\end{array}$ & $\begin{array}{l}\text { "Hand-crafting" licenses caused } \\
\text { inconsistencies, inefficiencies, and } \\
\text { frustration among reviewers and licensees. }\end{array}$ \\
\hline $\begin{array}{l}\text { Most interviewees perceived the escalating } \\
\text { fee structure as unfair and unrealistic. }\end{array}$ & $\begin{array}{l}\text { NRC's base of materials licenses was } \\
\text { continually eroding. }\end{array}$ \\
\hline $\begin{array}{l}\text { Guidance was outdated, too general, and } \\
\text { unconsolidated. }\end{array}$ & $\begin{array}{l}\text { Multiple submissions were required, } \\
\text { further delaying license issuance. }\end{array}$ \\
\hline $\begin{array}{l}\text { Many licensees were bewildered by the } \\
\text { process. }\end{array}$ & $\begin{array}{l}\text { License application became error prone, } \\
\text { time consuming, and, to a large extent, } \\
\text { costly. }\end{array}$ \\
\hline Rulemaking is time consuming. & $\begin{array}{l}\text { Guidance quickly became obsolete because } \\
\text { of advances in technology and/or changes } \\
\text { in business environments. }\end{array}$ \\
\hline
\end{tabular}




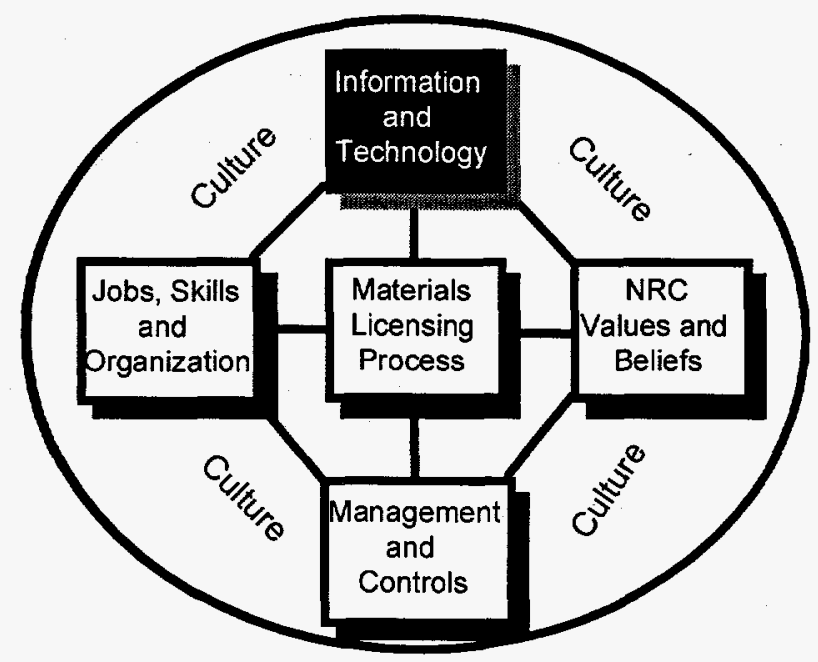

\subsubsection{Information Technology Findings}

NRC's old information technology (IT) was characterized by a proliferation of applications that were antiquated, disjointed, and redundant. As a result, many of these applications fell short of expectations. For example, the License Tracking System (LTS) did not capture some important licensee information. Other support tools, such as the WordPerfect macros for license generation, were not integrated with LTS and resulted in data redundancies. Most if not all reviewers found that LTS did not help them perform their jobs better. They viewed the applications more as a hindrance than as a tool.

Finding 1 - Supporting IT applications, particularly LTS, were antiquated, disjointed, and redundant.

Finding 2 - Modern IT was mismatched with personnel skills.

Finding 3 - Information Resources Management and its customers interacted adversarily and/or defensively.

See Table 4.2 for the potential consequences of these findings. 
Table 4.2. Information Technology Findings

\begin{tabular}{|l|l|}
\hline \multicolumn{1}{|c|}{ Finding } & \multicolumn{1}{c|}{ Potential Consequence } \\
\hline $\begin{array}{l}\text { Supporting IT applications, particularly } \\
\text { LTS, were antiquated, disjointed, and } \\
\text { redundant. }\end{array}$ & Integrity or validity of data was suspect. \\
\hline $\begin{array}{l}\text { Modern IT was mismatched with personnel } \\
\text { skills. }\end{array}$ & $\begin{array}{l}\text { NRC return on investment could be } \\
\text { limited. }\end{array}$ \\
\hline $\begin{array}{l}\text { IRM and its customers interacted } \\
\text { adversarily and/or defensively. }\end{array}$ & $\begin{array}{l}\text { Staff lacked confidence in support and } \\
\text { delivery of services. }\end{array}$ \\
\hline
\end{tabular}

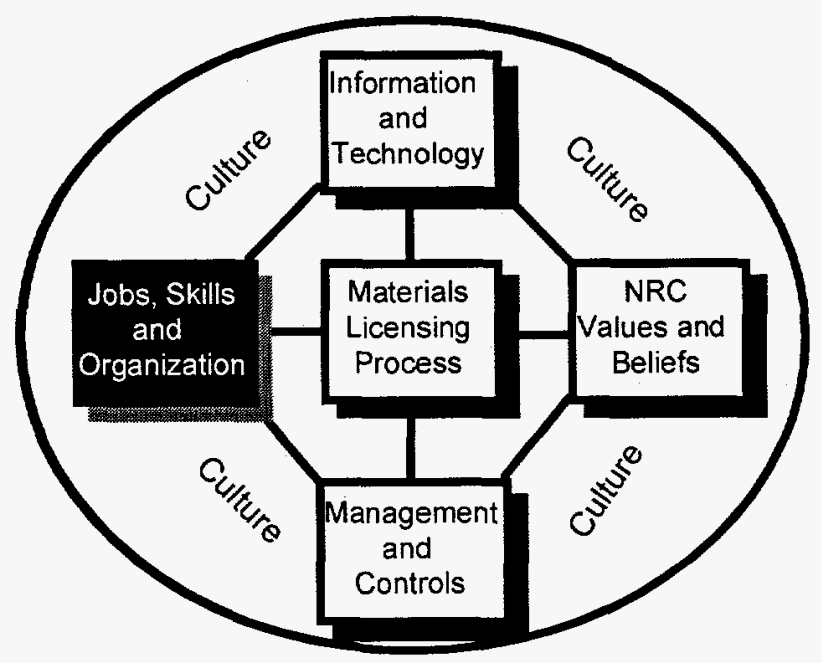

\subsubsection{Jobs, Skills, and Organization Findings}

The existing jobs, skills, and organizational characteristics (JSO) of NRC materials licensing staff were characterized by well-educated professionals, a mix of experienced and inexperienced license reviewers, and in some cases, staff members who do not yet possess the degree of computer knowledge to do their work as efficiently as possible or the belief that such knowledge is needed. In addition, the organization of the staff was inconsistent: Some regions had combined the license review and inspection function; others kept these separate as two distinct groups of staff.

Finding 1 - Technical reviewers met with inexperienced licensees.

Finding 2 - Technical staff had full authority and responsibility to decide technical issues.

Finding 3 - Technical reviewers received only informal training.

Finding 4 - Skills and job requirements were often mismatched. 
Finding 5 - NRC lacked a formalized mechanism to track materials technology advances

See Table 4.3 for the potential consequences of these findings.

Table 4.3 Jobs, Skills, and Organization Findings

\begin{tabular}{|l|l|}
\hline \multicolumn{1}{|c|}{ Finding } & \multicolumn{1}{|c|}{ Potential Consequence } \\
\hline $\begin{array}{l}\text { Technical reviewers met with inexperienced } \\
\text { licensees. }\end{array}$ & $\begin{array}{l}\text { The fewer the personal interactions, the more } \\
\text { problems and delays in completing } \\
\text { applications. }\end{array}$ \\
\hline $\begin{array}{l}\text { Technical staff had full authority and } \\
\text { responsibility to decide technical issues. }\end{array}$ & $\begin{array}{l}\text { The burdensome administrative process } \\
\text { undermined reviewers' primary role. }\end{array}$ \\
\hline $\begin{array}{l}\text { Technical reviewers received only informal } \\
\text { training. }\end{array}$ & $\begin{array}{l}\text { Time was lost in reconciling inconsistent } \\
\text { licensing decisions. }\end{array}$ \\
\hline $\begin{array}{l}\text { Skills and job requirements were often } \\
\text { mismatched. }\end{array}$ & $\begin{array}{l}\text { Significant work delays often lowered } \\
\text { quality or timeliness. }\end{array}$ \\
\hline $\begin{array}{l}\text { NRC lacked a formalized mechanism to } \\
\text { track materials technology advances. }\end{array}$ & $\begin{array}{l}\text { In some cases, licensees had more advanced } \\
\text { knowledge than NRC reviewers. }\end{array}$ \\
\hline
\end{tabular}

Jobs, skills, and organization findings indicated that training and information exchange could be significantly improved and that the staff had a strong desire to turn the informal training, staff interaction, and licensee interaction into more formal learning programs. The burdensome process interfered with both training and communication. Training changes could shorten cycle times, heighten morale, and improve license quality. 


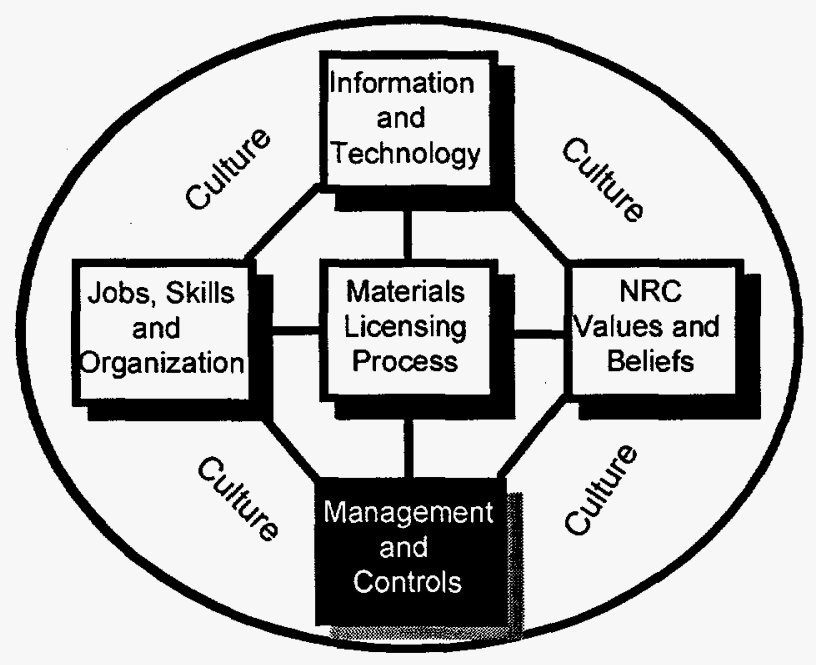

\subsubsection{Management and Controls Findings}

Management and controls were characterized by differing missions and customers in headquarters and regions. Headquarters (NMSS) sometimes had to make decisions to satisfy external clients, such as Congress and the public. Regions sometimes had to implement these decisions with little knowledge of their basis. Other issues that many reviewers believed impaired their day-to-day job performance and satisfaction were interruptions, prescriptive-driven goals, and technical assistance requests (TARs).

Finding 1 - Headquarters and regions have different and often conflicting missions and customers.

Finding 2 - Reviewers are frequently interrupted with other tasks.

Finding 3 - Numbers-oriented measurements ignore crucial performance goals.

Finding 4 - TAR rulings are untimely and generally inaccessible.

Finding 5 - Empowered, self-directed teams are essential.

See Table 4.4 for the potential consequences of these findings. 
Table 4.4. Management and Controls Findings

\begin{tabular}{|l|l|}
\hline \multicolumn{1}{|c|}{ Finding } & \multicolumn{1}{c|}{ Potential Consequence } \\
\hline $\begin{array}{l}\text { Headquarters and regions have different } \\
\text { and often conflicting missions and } \\
\text { customers. }\end{array}$ & $\begin{array}{l}\text { Headquarters policy decisions sometimes } \\
\text { displease reviewers and licensees. }\end{array}$ \\
\hline $\begin{array}{l}\text { Reviewers are frequently interrupted with } \\
\text { other tasks. }\end{array}$ & Reworks are a major source of inefficiency. \\
\hline $\begin{array}{l}\text { Numbers-oriented measurements ignore } \\
\text { crucial performance goals. }\end{array}$ & $\begin{array}{l}\text { Little or no focus is put on process } \\
\text { improvements. }\end{array}$ \\
\hline $\begin{array}{l}\text { TAR rulings are untimely and generally } \\
\text { inaccessible. }\end{array}$ & $\begin{array}{l}\text { Reviewers and licensees are confused and } \\
\text { frustrated. }\end{array}$ \\
\hline $\begin{array}{l}\text { Empowered, self-directed teams are } \\
\text { essential. }\end{array}$ & $\begin{array}{l}\text { Self-managed teams have raised } \\
\text { productivity, quality, and job satisfaction. }\end{array}$ \\
\hline
\end{tabular}

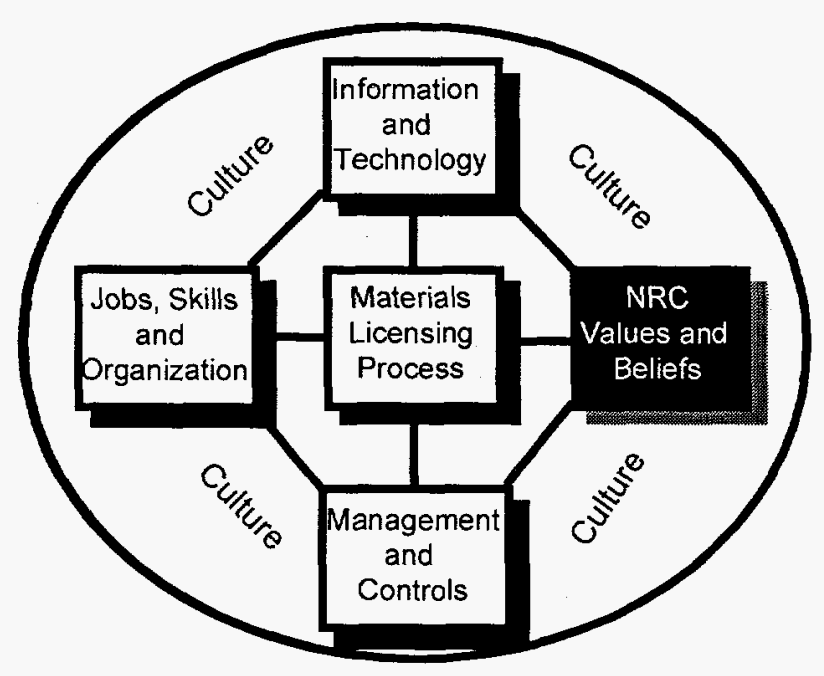

\subsubsection{NRC Values and Beliefs Findings}

NRC values and beliefs were characterized by the following contrasts:

- a strong focus on public safety, but little emphasis on the licensee as a "customer",

- a desire to make changes, but a skepticism that changes will happen, and

- an excellent track record for safety, but recognition of intense public fear of radioactive materials.

Finding 1 - Most NRC staff were ready for change; inertia was the biggest barrier.

Finding 2 - Inspections were required to be part of licensing.

Finding 3 - Public safety was a core value; licensee satisfaction was not. 
Finding 4 - The public demonstrates intense fear of radioactive materials; the agency was incident driven.

See Table 4.5 for the potential consequences of these findings.

Table 4.5. Values and Beliefs Findings

\begin{tabular}{|l|l|}
\hline \multicolumn{1}{|c|}{ Finding } & \multicolumn{1}{|c|}{ Potential Consequence } \\
\hline $\begin{array}{l}\text { Most NRC staff were ready for change; } \\
\text { inertia was the biggest barrier. }\end{array}$ & $\begin{array}{l}\text { Inertia overcame readiness, resulting in } \\
\text { incremental, not dramatic, change. }\end{array}$ \\
\hline $\begin{array}{l}\text { Inspections were required to be part of } \\
\text { licensing. }\end{array}$ & $\begin{array}{l}\text { Technical reviewer's lack of inspection } \\
\text { perspective lowered license quality and } \\
\text { increased inspector workload. }\end{array}$ \\
\hline $\begin{array}{l}\text { Public safety was a core value; licensee } \\
\text { satisfaction was not. }\end{array}$ & $\begin{array}{l}\text { Departing or dissatisfied "customers" meant } \\
\text { inefficiency. }\end{array}$ \\
\hline $\begin{array}{l}\text { The public demonstrates fear of radioactive } \\
\text { materials; the agency was incident driven. }\end{array}$ & $\begin{array}{l}\text { Time was lost in resolving relatively minor } \\
\text { incidents and preventing their recurrence. }\end{array}$ \\
\hline
\end{tabular}

The public should be given the opportunity to understand the actual as well as the perceived risk of the use of radioactive materials. Values and beliefs findings indicated that more education could greatly contribute toward decreasing the need for incidenttriggered rules and regulations.

\subsection{Redesign Ideas}

During the data collection process, NRC headquarters and regional managers and staff identified many excellent ways in which the licensing process could be redesigned. Many of these redesign ideas would be easy to implement and could rapidly and significantly improve the materials licensing process.

Major redesign ideas are summarized next. These are examples of what the redesign could include.

\section{Redesign Idea 1 - Simplify and standardize processing for routine categories of licenses.}

Discussion: NRC and its licensees know much more about radioactive materials than they did 30 years ago. Some categories of radioactive materials, such as gauges, are now established as predictable, safe to use, and of low risk to public health and safety. However, the licensing process for these relatively simple categories remains highly complex. 
This redesign idea proposed to dramatically simplify the processing of these low-risk materials categories. In many cases, control and quality inspection at the source manufacturer, combined with clear and graphic instruction in using the device, could potentially preclude NRC's need to strongly regulate the device's users.

Implementation result: Because this redesign idea would be relatively easy to implement, it could be assigned an early implementation priority. This idea would free up technical staff to focus on redesign ideas that take up more of the staff's time, such as issuing better guides and learning more about emerging materials technologies.

\section{Redesign Idea 2 - Extend license duration and/or cancel renewals.}

Discussion: NRC staff generally believes that requiring five-year renewals for all categories of licenses is unnecessary, whether for health or safety.

Many said that simple licensing categories could be exempted from the renewal requirement or that the requirement could be dropped altogether. Larger, more experienced licensees, such as large hospitals and universities, have technical experts to monitor and manage their program. Licensees who demonstrated their competency in safe use of materials could be granted a longer license of 10 or 15 years or more. Some staff members advocated dropping the renewal requirement altogether, moving NMSS from licensing and inspection to an auditing role.

Implementation result: The beneficial consequences of extending license renewals or dropping them altogether should have the same far-reaching effect as Redesign Idea 1.

\section{Redesign Idea 3 - Heighten interaction among inspectors, reviewers, and licensees.}

Discussion: Some staff redesign ideas centered on increasing interaction with the licensee, especially during the first three steps of the licensing process. In the early stages of the process, improving a licensee's understanding and providing guidance should result in fewer deficiencies and a quicker turnaround of Step 5 of a technical review (see current licensing process, shown in Appendix C).

Other ideas for increasing NRC interaction with the licensee follow:

- Increase training for staff who screen incoming phone calls.

- Channel a caller to the right staff person via a voice response system.

- Send applicants an understandable application kit.

A second area of interaction centered on the inspector. Especially in the case of renewals and amendments, increasing inspector communications with the licensee and the license 
reviewer should heighten understanding and speed all aspects of Step 5 of a technical review.

Implementation result: Besides establishing a better relationship with the licensee, this redesign idea should produce fewer application errors and better inspection results.

\section{Redesign Idea 4 - Redefine staff job descriptions and formalize training programs.}

Discussion: Some redesign ideas were in the area of job descriptions. As part of the strongly held belief that inspection and review go hand in hand, several NRC staff members advocated cross-training in these two disciplines. Many also proposed making work hours and places more flexible.

Other staffing redesign ideas focused on staff training, both in technical areas and in computer literacy. Because less experienced technical staff have been hired recently, many "long-timers" believed that formalized training was essential. Training redesign ideas extended to computer literacy, as discussed in Sections 4.2.2 and 4.2.3.

Implementation result: Reviewers would write each license category more consistently. Reviews would be faster. Staff would be used more effectively in their areas of trained expertise and licensees would benefit from the staff's increased knowledge and skills.

\section{Redesign Idea 5 - Replace LTS with a document-imaging distributed database.}

Discussion: Many staff members were blunt in expressing their suggestions for LTS, such as "junk it" and "kill it," and would replace it with a state-of-the-art central database. Some were more specific, stating the need for a Graphical User Interface (GUI) front-end in a UNIX-based client/server system.

All believed that the separate computer applications, especially LTS and Regulatory Information Tracking System (RITS), should be integrated. Some felt the integration must include the WordPerfect-based license. Many other ideas from the NRC staff fell within this general redesign idea as follows:

- Give licensees access to an on-line copy of rules and guides via, for example, Internet or FEDWORLD.

- Use more laptops in the field and transmit reports to the central database via phone modems.

- Develop all forms on-line in a fill-in-the-blank electronic format, especially the license itself, eliminating the need for printed forms. 
Most significantly, staff suggested including a document-imaging capability in the central database. Document imaging would-

- allow instant access to an electronic copy of all documents, such as the license application and subsequent letters,

- hold an electronic copy of all NRC staff-generated correspondence and the WordPerfect-generated license in the same electronic folder, so that word searches could be made,

- dramatically lower requirements for printing and distributing hard copy reports and license copies, and

- allow anyone instant access at any time to the current status of the processing of a license, the license itself, and even the entire docket file.

Implementation result: A central database with document imaging accessible anytime by any NRC staff person would-

- greatly shorten the time a licensee had to wait on the phone for status checks,

- eliminate the cumbersome milestone tracking within LTS, and

- eliminate untold staff hours consumed in looking for checked-out or misplaced docket files.

Most importantly, a state-of-the-art client server imaging database would dramatically streamline and simplify the entire licensing process.

\section{Redesign Idea 6 - Consolidate and cross-link rules, guides, policy, and TARs in an on-line hyper-text repository.}

Discussion: Interviewees agreed that a major revision to the existing body of regulatory and licensing information would significantly improve efficiency and accuracy. Several managers said that the key to such an undertaking is eliminating the serial nature of changes to a license, in which the reviewer must go back through the entire folder, page by page, to ensure all exceptions and contingencies are considered in any change to the license.

The new documentation should be modular, should allow cross-functional references, and should reduce redundancies. License reviewers must know that they are seeing the most current version of a rule, guide, or policy. Many said that changes to rules and guides must be immediately accessible to anyone. Some staff said that the consolidated documentation must also include "tie-downs." One regional staff member added the requirement that the consolidation should provide for quicker response from headquarters on all TARs.

The second-most-important aspect of consolidating the rules, guides, and policy is creating a single electronic repository that permits full-text search and one hyper-linked 
presentation of all documents for a given licensing category. This "hyper-text" technology is readily available today and is in widespread use in both the public and private sectors, such as in groupware applications.

Implementation result: Consolidating the rules, guides, and policies and making them available in a hyper-text on-line application would significantly increase the reviewers' comprehensiveness and accuracy in making technical decisions.

Table 4.6 Redesign Ideas

\begin{tabular}{|l|l|}
\hline \multicolumn{1}{|c|}{ Idea } & \multicolumn{1}{c|}{ Implementation Result } \\
\hline $\begin{array}{l}\text { Simplify and standardize processing for } \\
\text { routine categories of licenses. }\end{array}$ & $\begin{array}{l}\text { Technical staff freed to focus on better } \\
\text { guides and better understanding of materials } \\
\text { technology. }\end{array}$ \\
\hline $\begin{array}{l}\text { Extend license duration and/or cancel } \\
\text { renewals. }\end{array}$ & $\begin{array}{l}\text { Technical staff freed to focus on public and } \\
\text { licensee education. }\end{array}$ \\
\hline $\begin{array}{l}\text { Heighten interaction between inspectors, } \\
\text { reviewers, and licensees. }\end{array}$ & $\begin{array}{l}\text { Fewer application errors and better } \\
\text { inspection results. }\end{array}$ \\
\hline $\begin{array}{l}\text { Redefine staff job descriptions and } \\
\text { formalize training programs. }\end{array}$ & $\begin{array}{l}\text { Staff deployed more effectively; licensees } \\
\text { would benefit from staff's increased skill in } \\
\text { and knowledge of materials industry and IT. }\end{array}$ \\
\hline $\begin{array}{l}\text { Replace LTS with a document-imaging } \\
\text { distributed database. }\end{array}$ & $\begin{array}{l}\text { Licensing process dramatically streamlined } \\
\text { and simplified. }\end{array}$ \\
\hline $\begin{array}{l}\text { Consolidate and cross-link rules, guides, } \\
\text { policy, and TARs in an on-line hyper-text } \\
\text { repository }\end{array}$ & $\begin{array}{l}\text { Significant increase in comprehensiveness } \\
\text { and accuracy of rulings made by all } \\
\text { technical staff. }\end{array}$ \\
\hline
\end{tabular}




\section{Guide to Action}

\subsection{NMSS Licensing Vision}

The materials licensing vision is to have a materials licensing process that maintains or raises the current level of public safety and performs an order of magnitude faster than today's process.

\section{What is a vision?}

A vision is a clearly articulated set of outcomes and performance goals that solves the problems identified in the NRC's case for action. The vision evolved, becoming clearly defined as the BPR project progressed.

\section{Why is a vision needed in BPR projects?}

In defining the future NMSS licensing state, the BPR core team established performance measures to demonstrate achievements and challenging performance goals to stimulate creative thinking and new approaches.

In short, a vision-

- is a motivating "rallying cry",

- describes the strategic intent of the change process,

- is a vehicle for management consensus and alignment on the change campaign, and

- provides direction as the organization progresses to goals.

\subsection{Project Approach}

The rest of the project followed the BPR methodology to arrive at a proposed new materials licensing process that management could approve in logically related pieces.

The immediate next steps were defined and described below:

\subsubsection{Develop an "As Is" Process Model}

The NRC BPR core team validated the high-level "as-is" model, spending sufficient time to adequately capture a common set of key metrics and measures that described the old process or that will be used to ensure desired performance in the redesigned process, or both.

The key deliverables from this task were measures that captured the time, cost, and quality of the old process and that could be compared with those of the redesigned process. 


\subsubsection{Develop New Process Designs}

\section{Best-practices research expanded BPR core team thinking beyond their former operational domain and prepared the team to create the vision of the future licensing.}

Developing new design alternatives was an iterative process that involved the BPR core team in a series of sessions. This task, often called "best practice" research, showed the BPR core team what was technically possible with current technology and what other similar organizations are doing or are about to do. With this expanded perspective, the BPR core team thought creatively about possible new solutions to the licensing process that would achieve the desired performance objective.

\subsubsection{Develop Vision of the Future and New Designs}

The new materials licensing process is fully documented with appropriate high-level models, cost-benefit descriptions, and required changes.

This task developed and documented the vision and supporting products associated with a new materials licensing process. A fundamentally new process can be quickly accepted only if affected individuals and organizations take part in defining the process.

\subsubsection{Management Presentation}

The BPR team's recommendations were documented and then presented to NRC's senior management using the management model.

A key part of the management report was the BPR team recommendations for "chunking" proposed changes into logically related, implementable pieces. These followed naturally from a detailed analysis of the contemplated changes and their resulting impacts. The BPR team recommended two or three "waves of change" containing these chunks that would meet the charter goals. 


\section{Baselining the Process}

\subsection{Introduction}

\section{Metrics are an essential baseline for measuring the performance of both the old and new NMSS licensing process.}

The project's charter goal was to improve the speed of the former licensing process while maintaining or improving public safety. The baseline metrics presented in this section are the common set of key measures against which the old and new materials licensing processes would be compared.

\subsubsection{Licensee satisfaction with NRC licensing system service}

This measure was derived from licensee responses to the NMSS Regulatory Impact Survey of materials licensees regarding the effect of NRC's regulatory activities on their licensed operation. This comprehensive survey used 46 questions comprising several question types and response scales. Of the 46 question areas, the following 10 relate directly to licensee satisfaction:

- level of regulation

- cost of NRC regulation

- licensee understanding of review process

- guidance enabling licensees to file efficiently

- reviewer evaluations

- timeliness

- how delays affected the licensee facility

- how a licensee resolves disagreements with a license reviewer

- licensee perception of freedom to notify management about disagreement with license reviewer

- usefulness of regulatory guides

\section{Basis of Former Process Value}

The survey sought licensee views on the value of NRC regulations and policies, the licensing process, the inspection process, reporting requirements, and enforcement. The specific purpose of the section on materials licensing was to determine how effectively and efficiently NRC performed its licensing functions. A stratified random sample of 
600 NMSS materials licensees received questionnaires. Of these, 371 licensees responded as follows:

- Eighty percent believed that NRC regulation had increased; twenty percent believed that the level of regulation had remained the same.

- Fifty-eight percent felt free to notify management if they disagreed with a reviewer; twenty-seven percent did not; fifteen percent did not respond to this question.

- Ninety percent believed that the cost of complying with NRC regulations had increased over the past three years; ten percent believe that the cost of complying had remained the same.

This table presents the percentage of licensees who believed that they understood the review process the NRC used to issue, renew, or amend a license.

\begin{tabular}{|l|c|}
\hline License Action & Percent Understand \\
\hline Issue (new) & 44 \\
\hline Renew & 47 \\
\hline Amend & 51 \\
\hline
\end{tabular}

This table presents licensee perceptions of timeliness for various actions.

\begin{tabular}{|l|c|c|}
\hline License Action & Percent Timely & Percent Not Timely \\
\hline Issue (new) & 17 & 18 \\
\hline Renew & 29 & 37 \\
\hline Amend & 35 & 29 \\
\hline
\end{tabular}

This table presents licensee perceptions of delays on their operations.

\begin{tabular}{|l|c|}
\hline \multicolumn{1}{|c|}{ Scale of Problem } & Percent Agree \\
\hline $\begin{array}{l}\text { Serious or moderate } \\
\text { problem }\end{array}$ & 27 \\
\hline $\begin{array}{l}\text { Minor operational } \\
\text { problems }\end{array}$ & 22 \\
\hline No operational problems & 22 \\
\hline
\end{tabular}

This table shows how licensees resolved differences with license reviewers.

\begin{tabular}{|l|c|}
\hline \multicolumn{1}{|c|}{ Action Taken } & Percent \\
\hline Called reviewer & 62 \\
\hline Wrote to reviewer & 37 \\
\hline Never agreed & 36 \\
\hline Took no action & 12 \\
\hline Contacted management & 9 \\
\hline Met with reviewer & 8 \\
\hline
\end{tabular}


The licensees were asked a series of questions regarding various aspects of reviewer behavior and level of technical knowledge; their responses are presented in the following table. In general, these evaluations were very positive.

\begin{tabular}{|l|c|c|c|}
\hline \multicolumn{1}{|c|}{ Evaluation Area } & $\begin{array}{c}\text { Percent Agree } \\
\text { or Strongly } \\
\text { Agree }\end{array}$ & $\begin{array}{c}\text { Percent } \\
\text { Neutral }\end{array}$ & $\begin{array}{c}\text { Percent Disagree or } \\
\text { Strongly Disagree }\end{array}$ \\
\hline Professional & 71 & 19 & 3.5 \\
\hline Helpful & 61 & 22 & 9 \\
\hline Asked clear questions & 56 & 21 & 13 \\
\hline Technically competent & 54 & 27 & 14 \\
\hline Asked reasonable questions & 54 & 25 & 14 \\
\hline $\begin{array}{l}\text { Consistently applied } \\
\text { regulations }\end{array}$ & 52 & 25 & 15 \\
\hline $\begin{array}{l}\text { Asked only for relevant } \\
\text { information }\end{array}$ & 48 & 25 & 17 \\
\hline $\begin{array}{l}\text { Sufficient knowledge of } \\
\text { licensee operation }\end{array}$ & 46 & 25 & 16 \\
\hline
\end{tabular}

This table presents the percentage of licensees who agreed that NRC guidance enabled them to file new licenses, amendments, or renewals efficiently. In addition, 43 percent expressed confidence that NRC guidance would enable them to submit information acceptable to an NRC license reviewer.

\begin{tabular}{|l|c|}
\hline \multicolumn{1}{|c|}{ License Action } & Percent Agree \\
\hline Issue (new) & 34 \\
\hline Renew & 44 \\
\hline Amend & 49 \\
\hline
\end{tabular}

In addition to these responses, the team recognized the need to receive additional licensee feedback before implementing any new process. For example, licensee readiness to implement the new automated systems should be determined.

In addition, the team knew that implementation of BPR-recommended changes may not directly change licensee perceptions. Dramatic improvements in licensing process speed and efficiency and lower costs may not be reflected accurately in licensee perceptions. Opinions and beliefs are always influenced by many external factors, and the NRC licensing process is no exception. However, the team recommended that some type of systematic licensee feedback should accompany any changes to the materials licensing process. 


\subsubsection{Players and hand-offs: The number of distinct players involved in the process and the number of hand-offs among the players}

Hand-offs (HOs)are a major deterrent to efficiency of any process. Because interactions among players take time, particularly when interactions occur serially rather than in parallel, the more players and hand-offs, the slower the process.

The former eight-step materials licensing process averaged 52 players and 54 hand-offs (see Appendix C). In the worst case, 94 hand-offs can occur among the 52 players. The technical assistance request (TAR) process (see Appendix D) had 19 players and an average of 55 hand-offs. In the worst case, a TAR could involve 69 hand-offs.

These very high numbers of players and hand-offs were a major part of the delays encountered with the former process. Because different people managed the individual steps, each step was performed reasonably efficiently (given the work that had to be done in that step). However, no one person managed the overall process.

\section{Definitions}

Player: Individual or entity with a defined, significant role.

Hand-off: A point in a process step where work passes from one player to another. The maximum number of hand-offs (MHO) is the number of hand-offs in the worst case scenario. The routine number of hand-offs (RHO) is the number of hand-offs in a routine licensing action.

\section{Basis of Former Process Value}

The team examined the old eight-step current process model in detail, breaking each step down into its components. The team first determined the players in each step, then how each player interacted with other players in that step. Players are not always people. A player can be an entity, such as a system License Tracking System (LTS), a contractor running a system (NUDOCS), or a physical place (mail room).

The team then examined the interactions between players and noted where hand-offs occurred. The players (circles) and hand-offs (arrows) for Step 1 in the former materials licensing process are shown in Figure 6.1. 


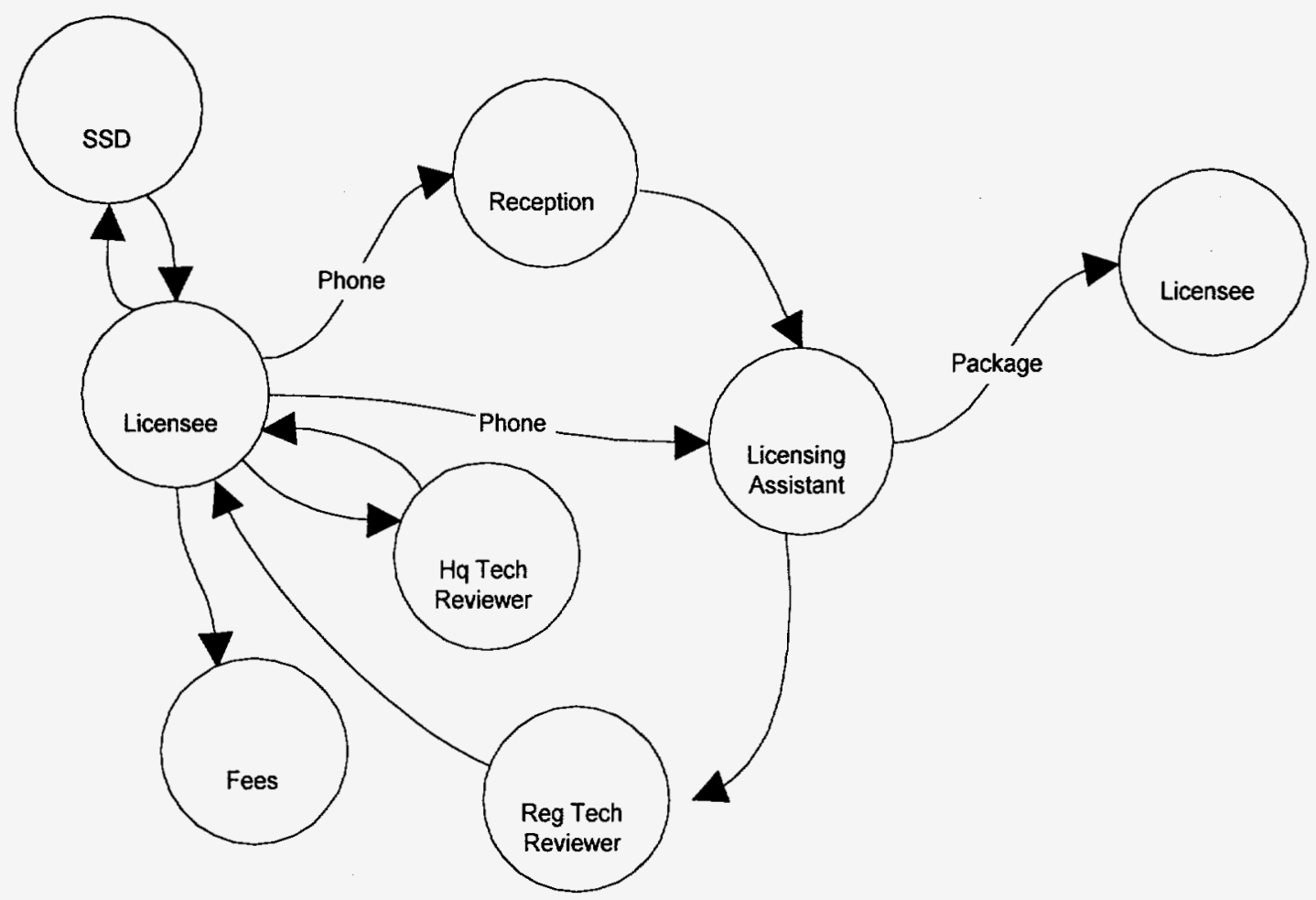

Figure 6.1 Players and Hand-offs in Step 1 of the Former Materials Licensing Process. Not counting the licensees' (or applicants') call to fees, seven players and five hand-offs occurred in Step 1 before the licensee application package was sent to the licensee.

The team used this approach to document the number of players and hand-offs in-

- each of the eight steps in the licensing process and

- the TAR process.

The results of this effort are shown on the two large diagrams, NMSS Materials Licensing Process chart and TAR Processing chart, in Appendices C and D, respectively.

In some cases, multiple hand-offs occur among players in a given step. The team developed both a RHO and a MHO sub-metric to capture the average and worst cases. 


\subsubsection{Processing time: Total work time required to complete each step}

\section{Definition}

Processing Time: The actual work time required to complete each step in the old eightstep materials licensing process. This metric is also known as touch time.

\section{Basis of Current Process Value}

The team used its individual and collective experience with the process to estimate the processing times for steps $1,3,4,5,6$, and 8 . The team excluded steps 2 and 7 because data was not available. The former processing time was 1.8 days.

\subsubsection{Cycle time: Total elapsed time required to complete each step}

\section{Definition}

Cycle time: The total elapsed or calendar time required to complete each step in the eight-step materials licensing process. Cycle time is equal to processing time plus dead time. In an ideal circumstance, dead time is close or equal to zero.

\section{Basis of Former Process Value}

The team derived most values for this metric from an Fiscal Year (FY) 94 LTS milestones report for all categories of licensing types (new, amendment, and renewal). The team used its individual and collective experience with the process to estimate the values for Steps 1 and 8 . The former cycle time for licenses was 84 days, and for TARs, it was 52 days.

\subsubsection{Accessibility of Information}

Many people - both the licensees and other external stakeholders, as well as NRC personnel-need many kinds of NRC information at many levels of detail. This information is contained in several NRC materials licensing databases and in such other sources as the local area network, LTS, regulatory guides, and licensing information. This metric measures how quickly such information can be obtained and how complete and accurate it is.

\section{Definition}

This measure has two components:

- a quantitative measure of the actual time needed to access required information and

- a qualitative measure of the information's accuracy and completeness. 


\section{Basis of Former Process Value}

The team used its individual and collective experience with the process to estimate the time necessary to access individual databases, to provide requested information to individuals, and to provide general information to interested parties. The team then estimated the quality of information obtained, assigning it a value from 1 (very complete and accurate) to 5 (neither complete nor accurate).

Note: Design of the new process took into account that elements of the former process such as LTS are valuable as part of the enterprise data model as well as being process components.

\subsubsection{Rework: Unnecessary feedback loops}

The rework measure consists of the following components:

- Review Downtime Index (RDI) per Action and

- Corrected Copies Rate

\section{Definition}

Review Downtime Index: The total time an action is available to be worked on by a technical reviewer, but is not being worked on because of other duties. The review downtime index is equal to the total cycle time, minus the total time awaiting deficiency responses, minus the total process time.

This indicator increases or decreases as interruptions increase or decrease during a license review. Reviewers interrupted during a review must often revisit parts of the application because they cannot recall the details of what they read before they were interrupted. This indicator thus correlates to rework in technical reviews.

\section{Basis of Former Process Value}

RDI per action is equal to the average cycle time per licensing action, minus the average time spent reviewing each licensing action and the average time spent waiting for licensee responses to deficiency letters or telephone calls. The team used data from LTS to determine the total number of licensing actions reviewed and the average cycle time for each licensing action during FY 94.

The team used LTS data to determine the average number of days spent awaiting deficiency responses from licensees per action: average days per deficiency response, multiplied by the number of deficiencies, and divided by the total number of licensing actions for the fiscal year. They used RITS data to determine the average review time per 
licensing action: total technical hours expended on all FY 94 licensing actions, divided by the total number of FY 94 licensing actions.

\section{Definition}

Corrected Copies Rate: The percentage of licensing actions for which a corrected version of the action is issued for any reason.

NRC corrects errors made in producing a materials license by producing a corrected copy of the license. The rate at which such corrected copies are issued measures expenditures of staff time outside the normal process.

\section{Basis of Former Process Value}

The team limited its sample to Region I and Region II and computed the number of corrected copies per licensing action by examining the number of corrected copies and the number of total licensing actions generated during FY 94.

Because Region l's files contained only copies of licensing prior licensing actions, bvut not the last action, some actions and some corrected copies issued during the year were omitted from the calculations. The files in Regions I and II contained a total of 145 corrected copies. The corresponding number of actions issued was 2109 , a corrected copy rate of $6.9 \%$. 


\section{Best Practices}

\subsection{Introduction}

"Best practice" research and site visits showed the BPR core team practical examples of what other organizations were doing or were about to do with current technology and organizational innovations. The team used this expanded perspective to create the vision of the future and to develop new design alternatives.

\subsection{Background}

Observing and researching the best practices described in this section expanded core team thinking beyond its current operational domain. The core team reviewed over 57 research articles and visited 10 sites. During the vision and design phases, the team defined a new materials licensing process derived in part from these "best practice" findings.

\subsection{Scope}

The team organized its research in a balanced set of categories that it derived from the five parts of the "business process diamond"(refer to Section 4 for the discussion of the process diamond). To these five categories, the team added two categories specific to the NRC mission. The sections that follow describe the research. The team focused on practical examples of what other organizations were doing or were about to do with current technology and organizational innovations.

\subsection{Steps of Best Practice}

The team conducted its research and arrived at findings in the following six steps:

- Determine best practice categories.

- Research best practice articles.

- Visit best practice sites.

- Analyze site visits.

- Develop major findings.

- Document all research and site visit findings.

\subsubsection{Determine Best Practice Categories}

The team derived categories by reviewing current articles and news reports for each part of the "business process diamond" model: materials licensing process; jobs, skills, and organization; management and control; values and beliefs; and information technology. To these five categories were added two categories that were specific to NRC's mission: 
regulatory product development and risk assessment. In all, the team developed the following best practice categories:

\section{Business Diamond:}

Materials Licensing Process (Section 7.5.1)

- Groupware

- Document Management

- Document Publication

Information Technology (Section 7.5.2)

- Client/Server Infrastructure

Jobs, Skills, and Organization (Section 7.5.3)

- Alternate Work Groups

- Learning Organization

Management and Controls (Section 7.5.4)

- Change Management and Leadership

Values and Beliefs (Section 7.5.5)

- Customer Service

NRC Mission-Specific

Regulatory Product Development (Section 7.5.6)

Risk Assessment (Section 7.5.7)

\subsubsection{Research Best Practice Articles}

Core team researchers surveyed hardcopy and on-line repositories of news articles and journal publications for current descriptions of examples of each best practice category, both theoretical and practical. The team found 57 relevant articles.

Everyone on the core team received copies of these articles. Working in pairs, the team reviewed the research articles, summarized key points, and then discussed how the insights contained in the articles were relevant to improving the NMSS licensing process. 


\subsubsection{Visit Best Practice Sites}

The core team visited the organizations listed in Table 7.1, spending between a half day and a whole day at each site.

Table 7.1 Best Practice Sites and Key Area of Focus

\begin{tabular}{|c|c|}
\hline Organization Visited & Key Area of Focus for the Visit \\
\hline $\begin{array}{l}\text { 1. Computer Sciences } \\
\text { Corporation } \\
\text { Fairfax, VA }\end{array}$ & $\begin{array}{l}\text { Document production with team writing and } \\
\text { automated production systems }\end{array}$ \\
\hline $\begin{array}{l}\text { 2. Vantage Technologies, Inc. } \\
\text { Chantilly, VA }\end{array}$ & $\begin{array}{l}\text { Document management, work flow, and televideo } \\
\text { conferencing }\end{array}$ \\
\hline $\begin{array}{l}\text { 3. Source One Finance } \\
\text { Herndon, VA }\end{array}$ & $\begin{array}{l}\text { Student loan services company with a remote } \\
\text { access on-line document management system }\end{array}$ \\
\hline $\begin{array}{l}\text { 4. Department of Education } \\
\text { Washington, DC }\end{array}$ & $\begin{array}{l}\text { Automated document management system for } \\
\text { processing and issuing funding grants }\end{array}$ \\
\hline $\begin{array}{l}\text { 5. Department of Energy } \\
\text { Washington, DC }\end{array}$ & Groupware application for 1,500 users \\
\hline $\begin{array}{l}\text { 6. American Institute of } \\
\text { Aeronautics and Astronautics } \\
\text { Washington, DC }\end{array}$ & $\begin{array}{l}\text { Professionals' association that recently underwent } \\
\text { business process reengineering, one outcome } \\
\text { being the creation of self-directed work teams }\end{array}$ \\
\hline $\begin{array}{l}\text { 7. Federal Communications } \\
\text { Commission } \\
\text { Gettysburg, PA }\end{array}$ & $\begin{array}{l}\text { Issues communications permits; instituted some } \\
\text { advances in automation }\end{array}$ \\
\hline $\begin{array}{l}\text { 8L. ELM Services } \\
\text { Rockville, MD }\end{array}$ & $\begin{array}{l}\text { Cancer program management organization that } \\
\text { recently undertook reorganization and team } \\
\text { building processes }\end{array}$ \\
\hline $\begin{array}{l}\text { 9. Peak Performance } \\
\text { Silver Spring, MD }\end{array}$ & $\begin{array}{l}\text { Multimedia training systems and consulting in } \\
\text { Electronic Performance Support Systems (EPSS) }\end{array}$ \\
\hline $\begin{array}{l}\text { 10. NRC High Level Waste } \\
\text { Computing Center } \\
\text { Rockville, MD }\end{array}$ & Document management \\
\hline
\end{tabular}

Noté: Each site illustrated far more instances of best practices for possible use in the vision and redesign phase than the specific best practices the team had gone to see in action.

\subsubsection{Analyze Site Visit}

Immediately after each site visit, often while still on site, the team conducted a wrap-up "take-away" workshop. Each team member was asked to describe a key finding he or she saw during the visit. The team reviewed, discussed, and recorded these notes as important reference documents for the next step. 


\subsubsection{Develop Major Findings}

The team developed major findings in teams of two; each team looked at summarized findings from research articles and from site visits. Each team derived from two to four major findings for each best practice category; these are reported in Section 7.5.

\subsubsection{Document All Research and Site Visit Findings}

The team assembled the major findings and discussed each one. The team also assembled all supporting research articles and notes from site visits for use in the next step in BPR, Vision of the Future.

The team continues to seek out best practices in the Agreement States, other Federal agencies, and private industry.

\subsection{Best Practices Research}

\subsubsection{Materials Licensing Process}

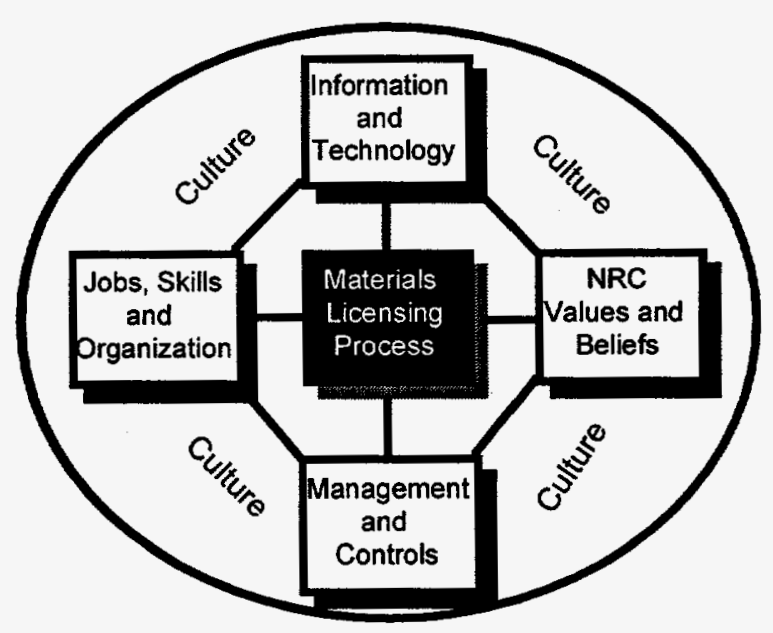

\section{(1) Groupware}

Groupware is an integrated framework of tools, to include a document and image management system, group decision support systems, shared screen environments, calendaring, and e-mail. Table 7.3 shows some of the functions for several groupware categories. 
Table 7.3 Site Visit Relevance to Best Practice Categories

\begin{tabular}{|l|l|}
\hline \multicolumn{1}{|c|}{ Groupware Tool Category } & \multicolumn{1}{|c|}{ Function } \\
\hline Shared memory and database & $\begin{array}{l}\text { Single source of information accessible to all group } \\
\text { members }\end{array}$ \\
\hline Document and image management & $\begin{array}{l}\text { Simultaneous retrieval and annotation of images, text, } \\
\text { graphics, and computer data }\end{array}$ \\
\hline Group decision support systems & $\begin{array}{l}\text { Decision structuring, idea generating, voting, ranking, } \\
\text { and concurrence }\end{array}$ \\
\hline Shared screen environments & $\begin{array}{l}\text { Simultaneous display of work product to multiple } \\
\text { users for collaboration in real time; seamless media } \\
\text { transfer across applications }\end{array}$ \\
\hline Groupware development & $\begin{array}{l}\text { Generation and maintenance of groupware databases } \\
\text { and supporting products }\end{array}$ \\
\hline Calendaring and scheduling & $\begin{array}{l}\text { Electronic development of mutually agreeable group } \\
\text { schedules }\end{array}$ \\
\hline E-mail and other messaging tools & $\begin{array}{l}\text { Rapid, dependable, and achievable staff } \\
\text { communications }\end{array}$ \\
\hline
\end{tabular}

The benefits of groupware include the following:

- Workers who have the appropriate groupware tools and access to databases can be highly effective.

- Groupware enables and encourages peer technical collaboration.

(2) Document Management

Automated document management converts paper-based systems to electronically indexed media for remote site access. Workflow automatically routes electronic documents. System components include an automated scanning system that converts paper-based documents into an indexed computer database.

Converting data into electronic media and indexed electronic folders also achieves the following:

- Reduces the errors introduced into databases.

- Increases end-product quality and accuracy. 
Encouraging the use and acceptance of documents in an electronic format further increases efficiency. For the following reasons, having all such information in a central electronic repository saves users a significant amount of time:

- Workflow software speeds document routing and management and ensures adequate security.

- "One-stop-shopping" requires inputting information only once and making it available to all authorized people.

\section{(3) Document Publication}

Best-practice document publication reduces the time and resources necessary to compose, edit, and obtain agency-wide concurrence. Components include commercially available desktop publishing software, automated electronic scanners, high-speed electronic editing stations, and high-speed color and black-and-white printers.

Trained and disciplined publication work teams transcend organization boundaries and contribute to a faster turnaround time. Converting documents from a paper-based system to an indexed electronic media format lets the publication team quickly capture, archive, retrieve, and create new documents. Using electronic signatures and concurrence, combined with encouraging electronically submitted and issued documents (such as paperless licenses, correspondence), also speeds production. For the following reasons, software and selected groupware manage indexed electronic media universally and ensure that documents are issued rapidly:

- Sophisticated, commercially available desk top publishing (DTP) technology and groupware, high-speed automated electronic scanners, electronic editing stations, and printers have closed the gap between publisher, editor, and printer.

- Highly trained, disciplined work teams can produce almost every kind of document.

- Using electronic concurrence, electronic signatures, and simultaneous document routing, significantly speeds publication turnaround time. 


\subsubsection{Information Technology: Client/Server Infrastructure}

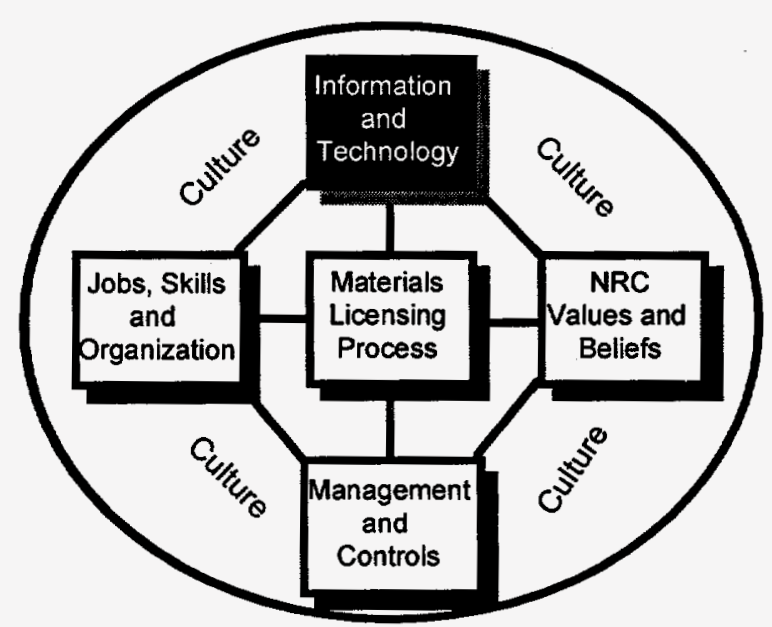

A client/server infrastructure is a computing environment characterized by intelligent workstations, or clients, connected by Local Area Networks (LANs) or Wide Area Networks (WANs), or both, to various mini-computers or mainframe computers, or servers. The benefits of deploying a client/server infrastructure include the following:

- New Commercial, Off-the-Shelf (COTS) groupware and document managfement products are no longer mainframe-based.

- A client/server infrastructure offers a much more reliable computing environment.

- A client/server infrastructure enables rapid application development.

- A client/server infrastructure is inherently more complex to operate than the traditional mainframe infrastructure. 


\subsubsection{Jobs, Skills, and Organization}

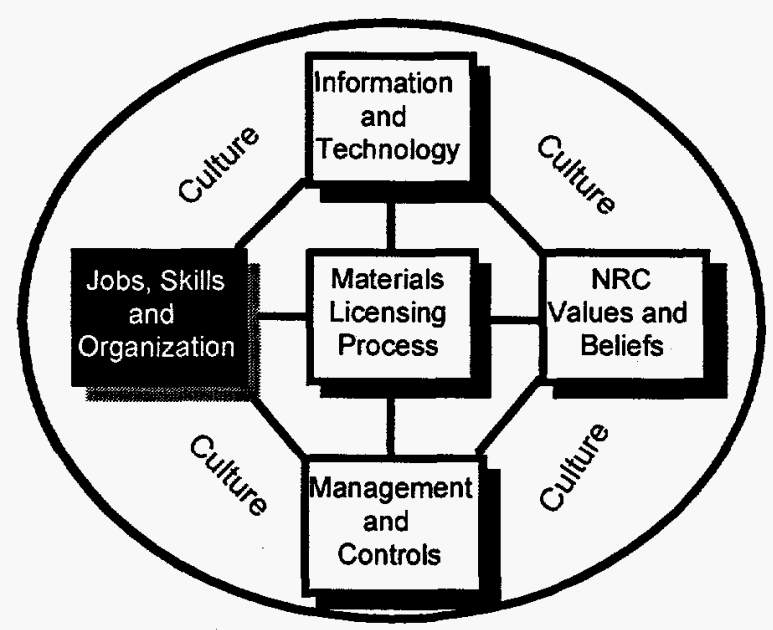

\section{(1) Alternate Work Group Structures}

An empowered work group consists of teams of people with complementary skills who are committed to a common purpose, a common set of performance goals, and a common approach for which they hold themselves mutually accountable. Using alternative work groups requires that managers give workers the responsibility, authority, and information to make key organization decisions. The benefits of using alternative work groups include the following:

- A self-managed work team, or an alternative work group, can perform major portions of critical work processes.

- All parts of an organization can use self-managed work teams to deliver products and to help achieve its overall mission.

\section{(2) Learning Organization}

A learning organization is one in which the members create, acquire, and transfer knowledge and insights; modify their behavior; and continually improve in providing services for the customer. Recent innovations in learning techniques, combined with advances in technology, have created this fresh new way of carrying out training and education. The benefits of a learning organization include the following:

- The new "organization learning" method is like an ongoing BPR project.

- Management and measurement are key to linking learning organization activities to continuous process improvements.

- Technology is the key "driver" of the new learning organization model.

- Training can take place in classrooms or on the job; it can be delivered from a central hub or from a regional site. 


\subsubsection{Management and Controls: Change Management and Leadership}

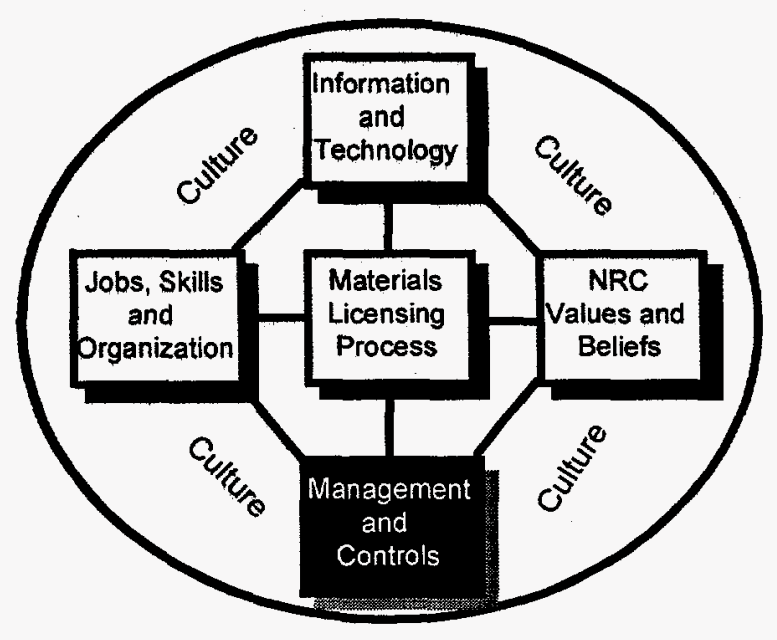

Change management combines designing the future organization for a business area with developing and implementing transition strategy to achieve that future state. Strong leadership and advocacy are essential to a change program and include the following:

- Change management focuses on shifting staff attitudes and beliefs toward customer focus and responsiveness to the customer.

- Making processes faster and more customer-focused requires giving workers new technology and authority.

- Developing organization policy quickly requires streamlining organizational approval processes.

- Senior management's advocacy of change is a major part of effective change management. 


\subsubsection{Values and Beliefs: Customer Service}

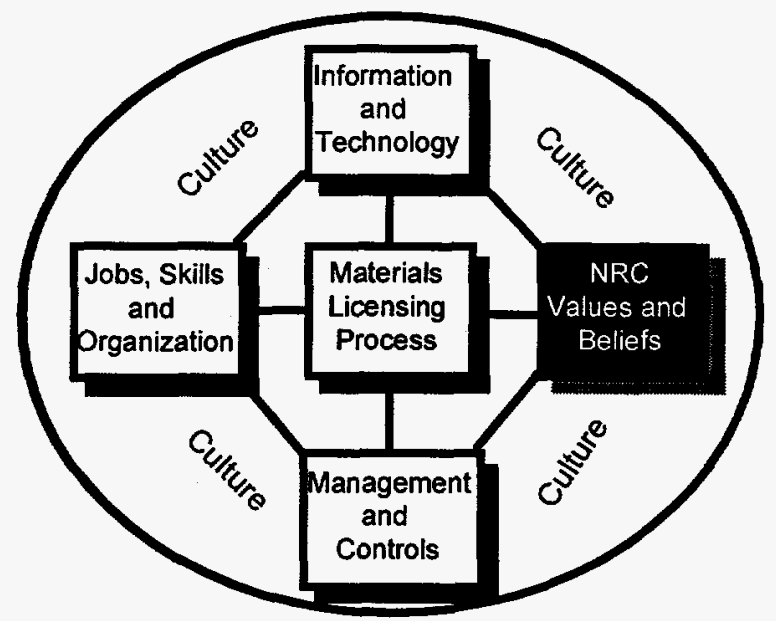

Tremendous improvements in customer service in the commercial sector have raised the public's expectations. The highest quality customer service delivers more service than the customer expects; anticipates customers' needs before they even envision them; and delivers timely, defect-free products. Communications with customers are clear, polite, and tailored to the customer's needs. The following statements apply to customer service:

- Customers want easy, rapid, and reliable access to up-to-date information.

- Organizations that make it easy for customers to submit complete applications greatly reduce turnaround time.

- Organizations achieve quality customer service when they empower employees to satisfy the customer and give employees the authority to solve the customer's problem.

\subsubsection{Regulatory Product Development}

Regulatory product development is an ongoing process to-

- identify needs for changes in regulations or policy,

- ensure that the regulatory process reflects the current state of technology that uses licensed materials,

- adapt the regulatory framework to meet evolving public and licensee needs,

- continually examine the information needs of licensees, the staff, and the public, and

- develop the needed products. 
The following statements apply to regulatory product development:

- Observing and communicating with the user are the best ways to determine the user's needs.

- A new product can be developed quickly if designers first develop an imperfect version rapidly, then improve it by observing its flaws and how it is actually used.

- Concurrent development speeds the development of new products and improves their quality.

\subsubsection{Risk Assessment}

Risk assessment is an objective, consistent, and repeatable process for assessing risk to the public, the customers' workers, and the environment as part of performing a service.

The following statements apply to risk assessment:

- Government and industry are increasingly using risk assessment to justify and defend actions.

- On-line expert systems and risk assessment scripts can greatly speed and standardize a process. 



\section{Vision of the Future Materials Licensing Process}

\subsection{Introduction}

The BPR core team's vision of the materials licensing process was designed to meet the charter goals. This section describes the vision that was used to design the new licensing process.

\subsection{Visioning Process}

The team synthesized inputs from several sources to produce a new operating vision. Sections 1-4 document the licensing process requirements, the staff's perceptions of problems with the current process, and many possible redesign solutions.

The team then evaluated the old process, developing a set of initial measures that described current process performance in such terms as steps, cycle time, and cost. (See Section 6, "Baselining the Process.") The team gained a well-grounded perspective on process areas that cause significant performance and other problems and on those that offer major opportunities for improvement.

The team then looked at other private and government organizations that were using modern technology in performing functions similar to NRC's licensing process.

With that background, the team synthesized all the requirements and possible redesign ideas into a vision of the new process. The vision is depicted in Figure 8.1. 


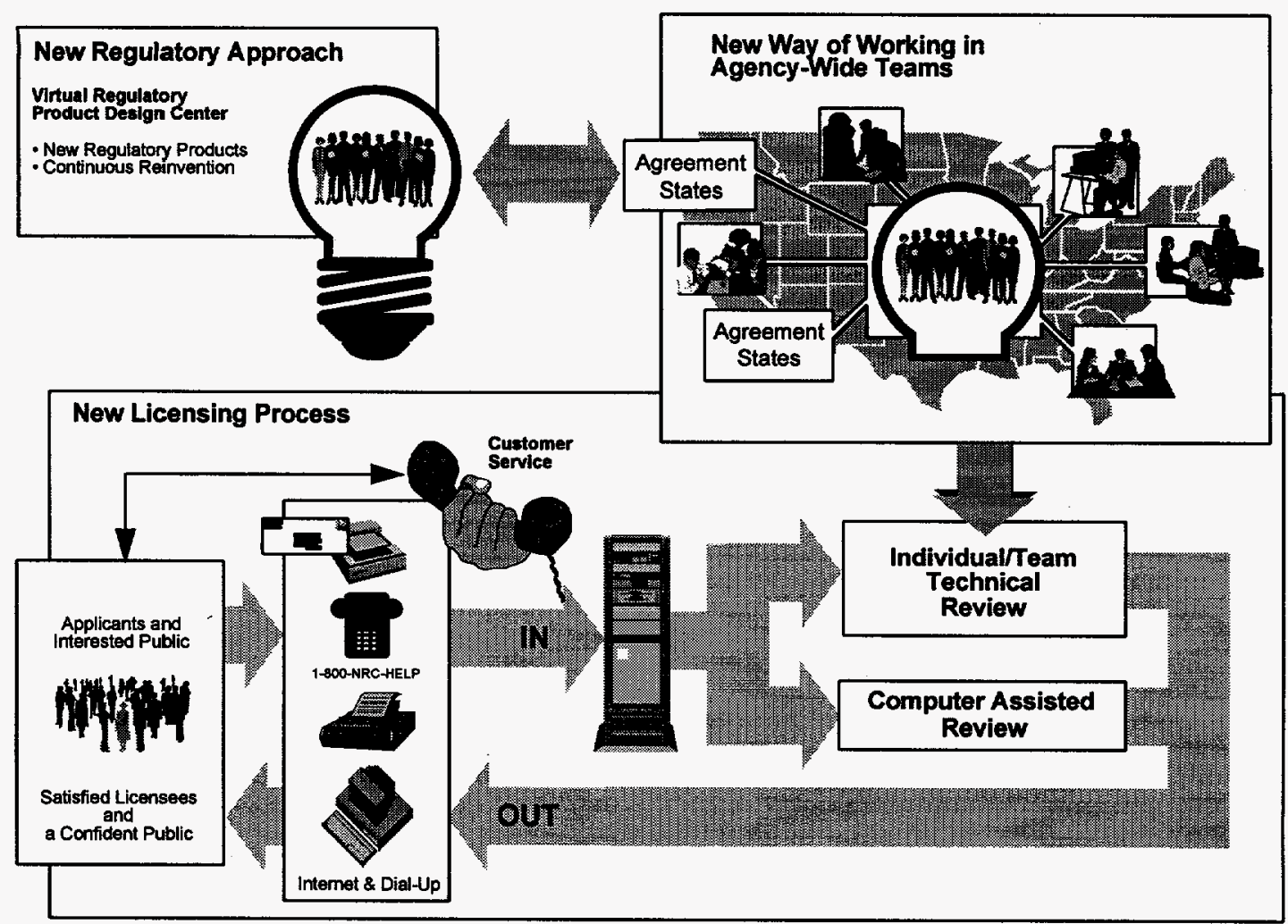

Figure 8.1 - New Materials Licensing Process Vision. The new licensing process links the materials licensing community.

After validating and updating the vision (as described earlier), the team began to define both the benefits and impacts of the new design. The principal components of the license granting process are illustrated in Figure 8.2. 


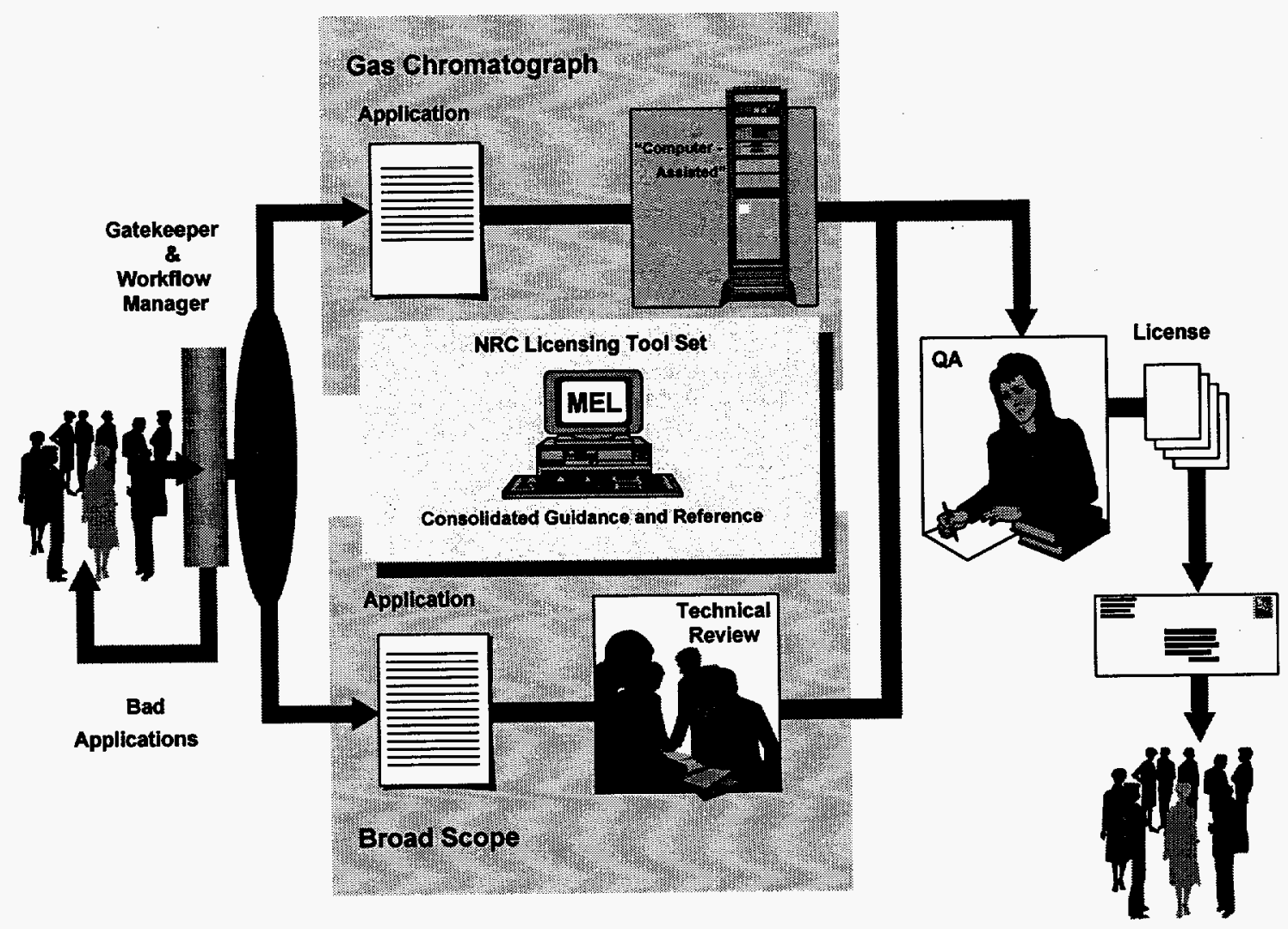

Figure 8.2 License Granting Paths. Each application will be reviewed based on its complexity and associated issues.

Significantly different products are required to support the new process. Central to this new licensing process is the development of the Materials Electronic Library (MEL) repository. The concept for this repository is depicted in Figure 8.3. 


\section{Collect and Analyze Existing Guidance}

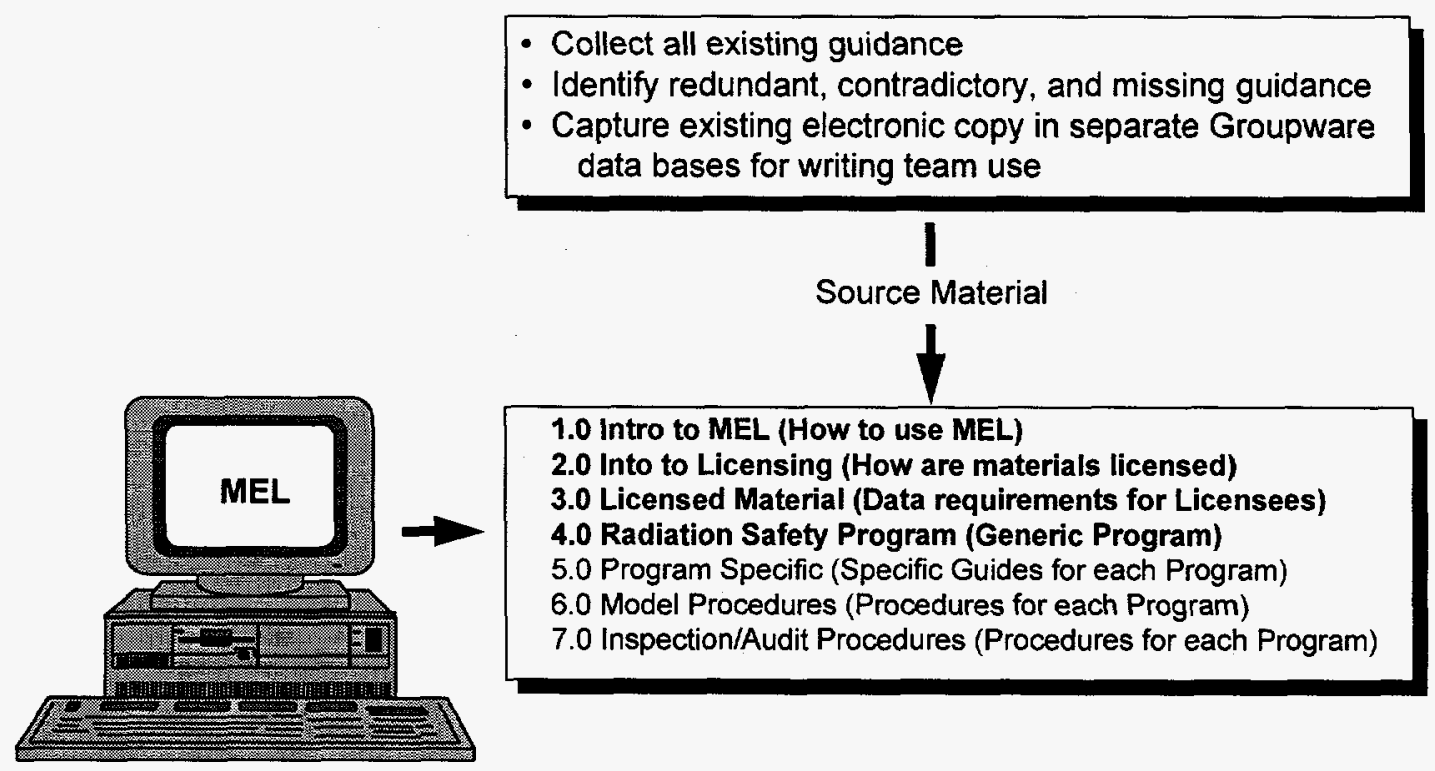

Figure 8.3 MEL Concept. MEL will consolidate all NMSS guidance and reference material.

The MEL concept creates a single electronic repository of licensing guidance for use by NRC staff, licensees, and all other stakeholders. MEL's first four sections will be composed of generic information, modular components that apply to all types of materials licenses and that will be reused in later sections. Sections 5, 6, and 7 of MEL will use the same basic structure as Section 4 in MEL, but address specific program code differences from the general model. 
Regulatory products for a particular technology or issue will be produced or updated quickly and in parallel; thus ensuring proper integration. To accomplish this, a crossfunctional team will work in the manner depicted in the example Figure 8.4.

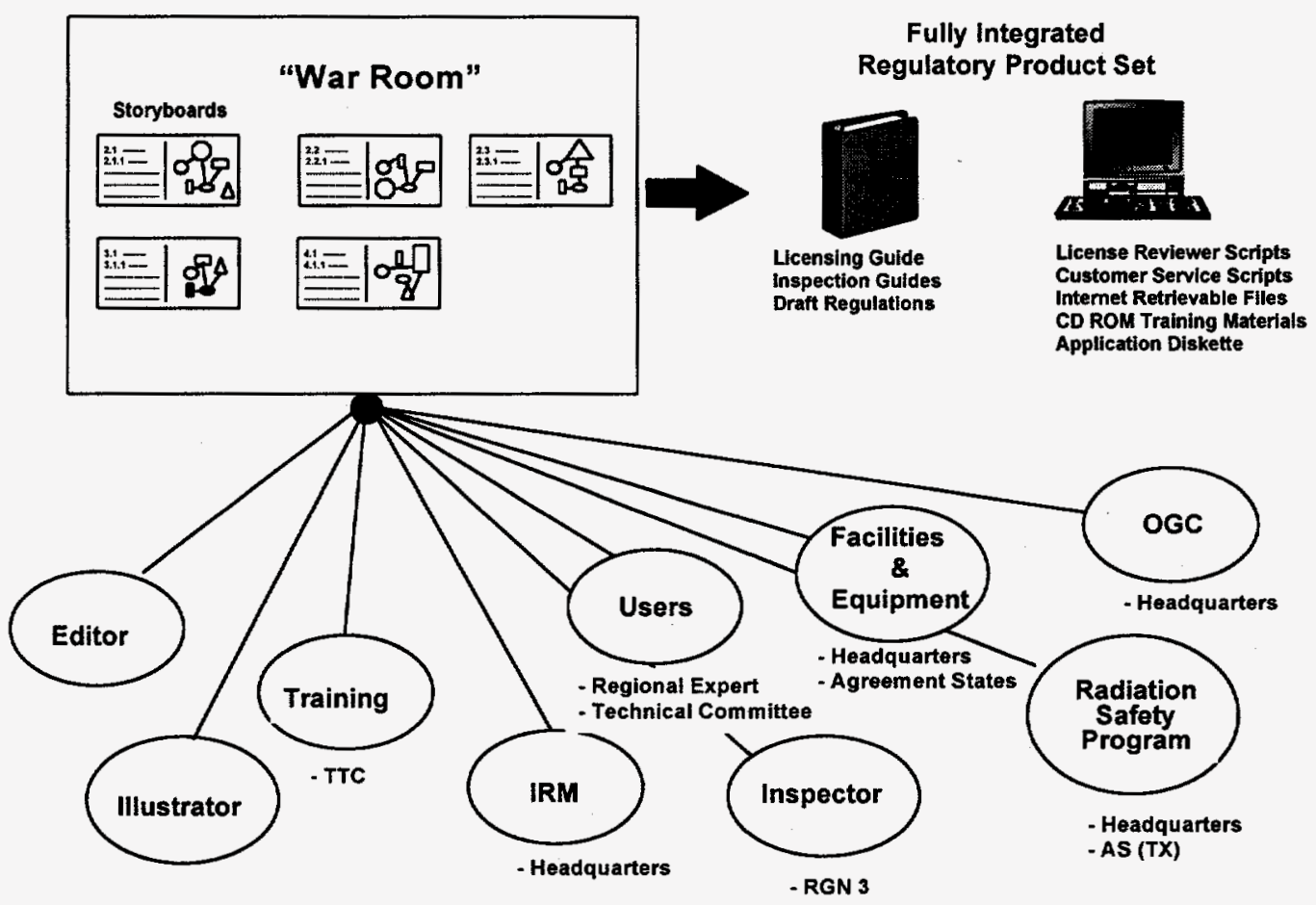

Figure 8.4 Accelerated Regulatory Product Set Development. A new, integrated product set will be required to support the new process-a product set assembled quickly by a cross-functional team assembled from across the materials program community using up-to-date development tools and publishing techniques. 
Management and public review at appropriate points in the process ensures product completeness, quality, and usability. The team will assemble for a short time at the kickoff session and only as needed thereafter, using groupware tools to collaborate as a team without necessarily being physically co-located. At the end of the development cycle, the team will disband.
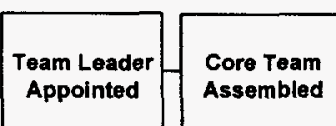

-2-3 People

- Editor

- Illustrator
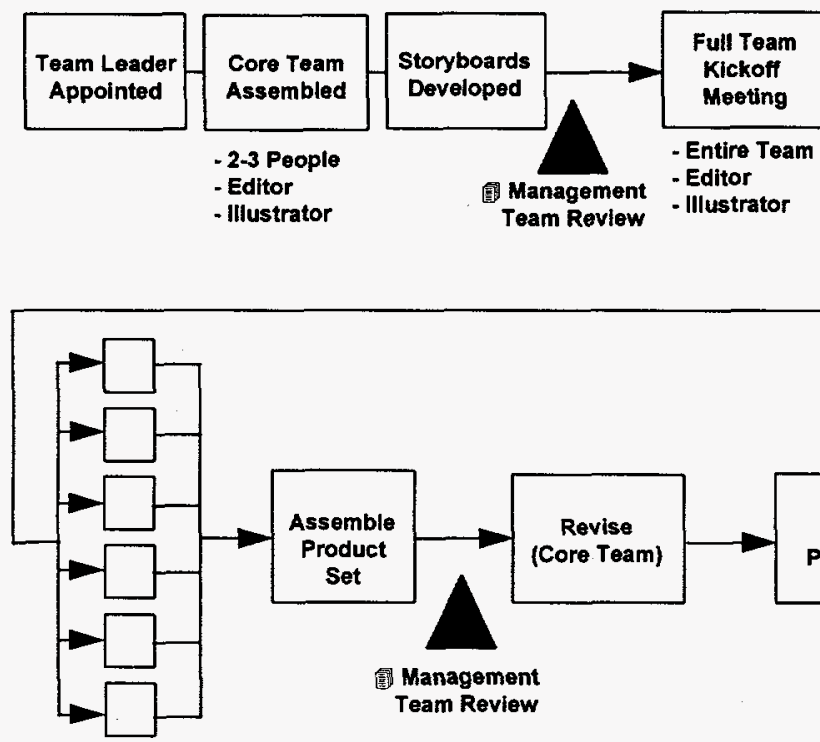

Team Operating Principles

(i) Common Purpose

面 Define Member Roles

issign Product Leaders

(2) Develop Communication Links

Authorize Cross-Level Coordination

- Groupware Enabled

Parallel Product Development

Figure 8.5 Product Development Team Operations and Flow. The entire product team will meet together at the kickoff meeting and only as needed thereafter. 


\subsection{Business Diamond Area Requirements and Potential Impacts}

Implementing the new process requires changes in the NMSS licensing community. The discussion in this section centers on the principal changes that must be made before the new process can be implemented. As in prior sections, the discussion is organized around the business diamond areas. This technique forces a disciplined approach to a comprehensive description of the entire magnitude of change in all its dimensions.

\subsubsection{Major Process Requirements and Potential Impacts}

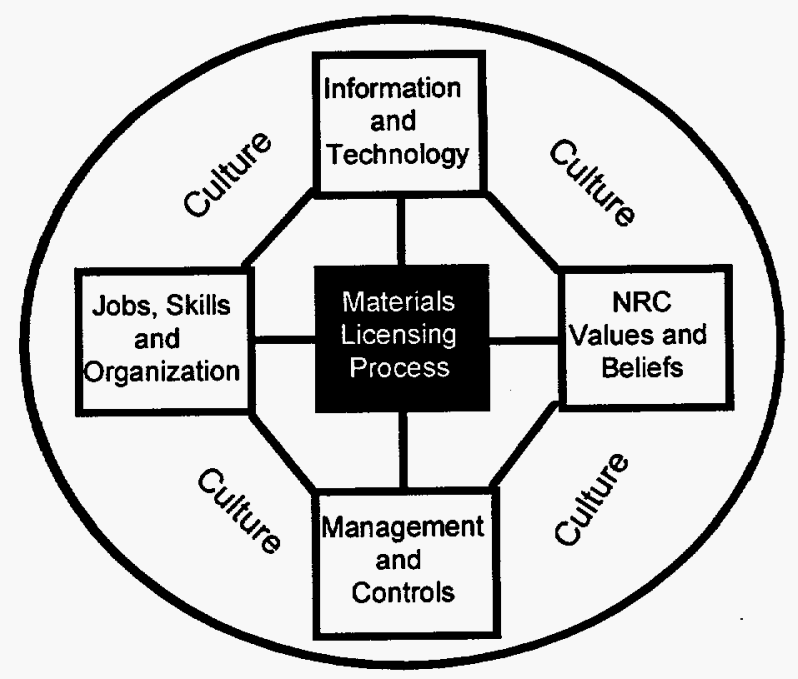

(1) Single authoritative database of all licensing policy and guidance

Potential Impact: The new licensing process requires that NRC embody its licensing policy and guidance into an integrated, easily accessible electronic database.

\section{(2) A single process owner}

Potential Impact: Regions and headquarters all use the same process to issue materials licenses. A single process owner needs to be designated. This owner-

- manages the materials licensing process from beginning to end,

- has the authority to change the process to make it more efficient and effective, and

- uses automated work flow tools to ensure that work performed by geographically separated staff is routed and controlled promptly and efficiently.

(3) Early focus on quality assurance reviews

Potential Impact: Moving to any new process will require considerable work to ensure maintaining product quality. Thorough and comprehensive quality assurance reviews must be conducted to ensure that there is no adverse impact on public health and safety. 


\section{(4) Regulatory Product design center}

Potential Impact: One of the most important components of the new process is a design center for developing regulatory products. This design center draws on staff throughout $\mathrm{NRC}$, and in some of the Agreement States, as a specific knowledge or expertise is needed.

This massive change in developing regulatory products requires creating a skills database in order to quickly locate the expertise needed to produce a given product.

\subsubsection{Information and Technology Requirements and Potential Impacts}

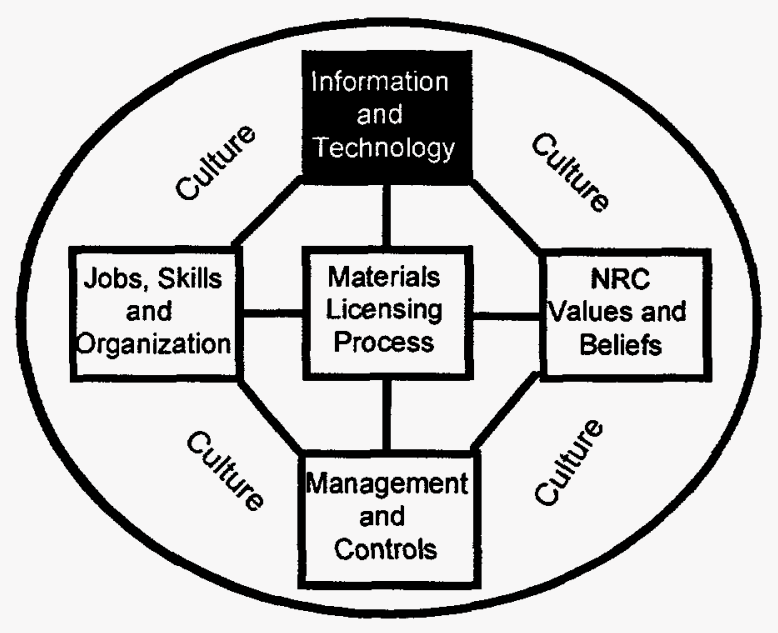

(1) Selection of new equipment and software

Potential Impact: The selection of new equipment and software must conform to NRC's policies and procedures. The process includes-

- matching existing system capability with new process needs,

- ensuring adequate performance of the new system, and

- surveying and leveraging existing NRC systems, such as the High-Level Waste Computing Center. 


\section{(2) Rapid purchase of new equipment and software}

Potential Impact: A rapid procurement cycle must be initiated to obtain the selected equipment and software. This new procurement cycle includes-

- resource identification,

- contracting actions,

- warehousing and configuration management of equipment and software as it arrives, and

- a phase-in plan that includes a BPR Phase II laboratory requirement as well as longterm roll-out implementation requirements (the laboratory for Phase II will be selected and configured with appropriate LAN/WAN support in concert with end users.)

\section{(3) Short- and long-term technology support}

Potential Impact: IRM support is required to develop new approaches, techniques, and transition plans. NRC needs to identify an overall transition plan and new support contractors, epecially for such areas as ongoing tool development and upgrades.

\section{(4) Significant training in new technology}

Potential Impact: Training requirements take two principal forms:

- End users need to upgrade their computer skill base to understand and use Windowsbased applications.

- IRM support staff needs "just-in-time" training for the new equipment and software.

\section{(5) Migration and transition plans}

Potential Impact: At the present time various NRC organizations are using "legacy" applications and data, such as LTS and RITS. As long as these databases are in use, the new licensing system must maintain their currency. To leverage new capabilities as they are brought on-line, the new licensing process should be synchronized with the ongoing NRC strategic plan and other IT and document transition initiatives. 


\subsubsection{Jobs, Skills, and Organization}

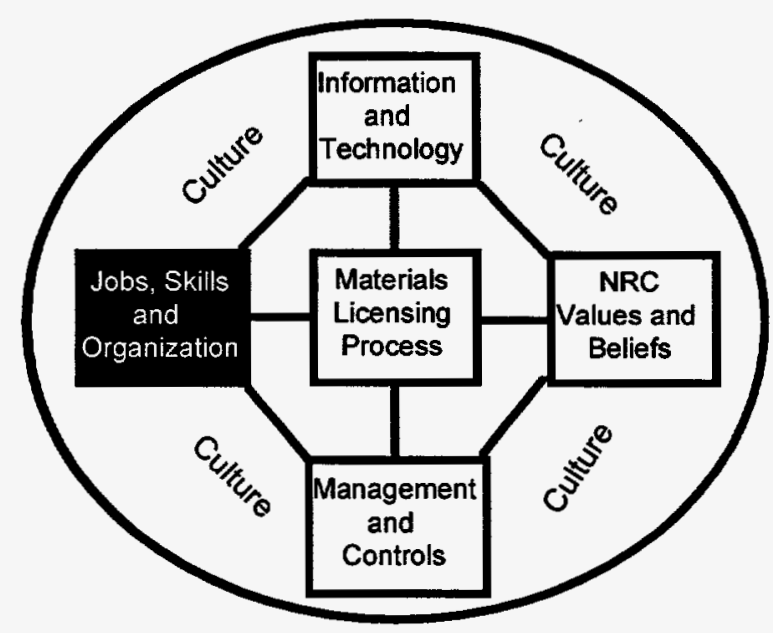

(1) Job classifications matched to the new organization

Potential Impact: Implementing the vision will potentially include creating new job descriptions.

In the short-term, people may resist change. Some jobs will change dramatically; some job descriptions may disappear. Some people will need significant training before filling the new jobs. In the long run, however, the potential results should be-

- higher morale throughout NRC,

- enhanced technical competency, and

- better matched individuals and jobs.

\section{(2) Employees with new and enhanced skills}

Potential Impact: NRC will place additional emphasis on team building, meeting management techniques, and interpersonal skills. In addition, the staff will be encouraged to acquire or upgrade their skills in groupware and document management, as well as their generalized computer-based skills.

Participation in the new regulatory product design center will enable and enhance the current slate of technical skills, such as health physics, nuclear engineering, and risk analysis. Document editing and publishing skills will be integral to the new process. 


\subsubsection{Management and Control Requirements and Impacts}

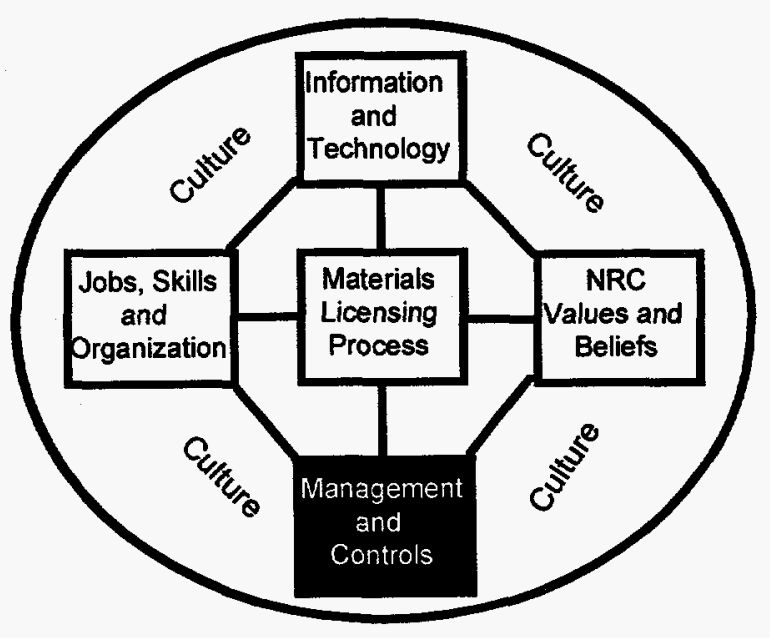

(1) Empowered workers

Potential Impact: In a self-managed work team (SMWT) environment, managers facilitate and coach the workers. NRC managers would focus on process, not individual, performance to-

- facilitate such matters as on-line case assignments and productivity issues,

- support geographically divergent SMWTs in accomplishing various agency goals/missions, and

- give workers the necessary tools to accomplish their jobs successfully.

(2) Highly responsible, accountable team members

Potential Impact: New measurements are needed for assessment of team-based performance. 


\subsubsection{NRC Values and Beliefs Requirements and Impacts}

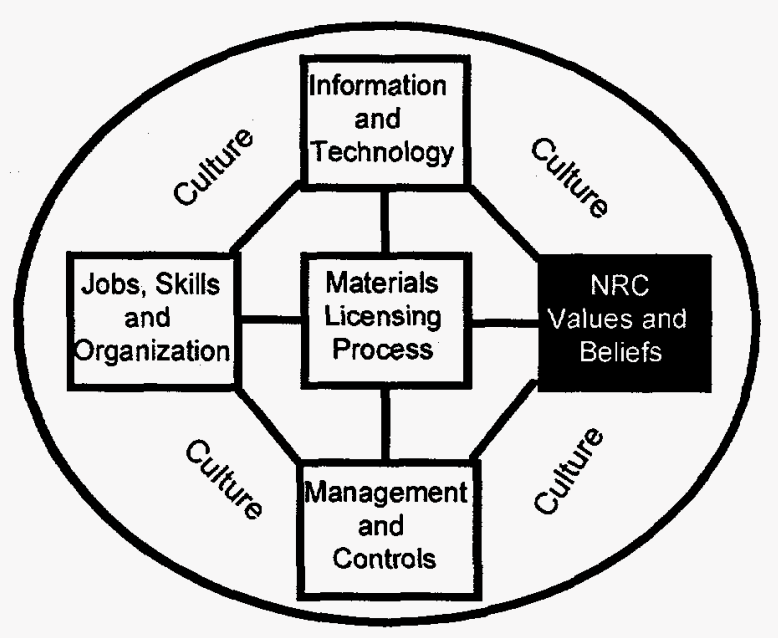

(1) Continued focus on public health and safety

Potential Impact: Implementing the new process requires developing and using new diagnostic measures to evaluate the impact on public health and safety. These include measures of licensee performance (such as reportable events) and agency performance (such as developing regulatory products promptly).

\section{(2) Agency-wide focus on customers}

Potential Impact: Decisions on applications and other information requests should be made promptly. All information products should be easy to read and understand as well as technically accurate. To minimize the need for follow-up communications, all needed information should be submitted at the first request. In order to continually improve the process and its products, NRC encourages and enables feedback from all its customers.

\section{(3) NRC as a single team}

Potential Impact: NRC employees are encouraged to function as team players or coaches.

NRC management and staff are encouraged to adopt the attitude that there is no disgrace in falling down, only in lying there and not getting up. Innovations and risk taking is to be encouraged and rewarded. Lessons should be learned from mistakes, and should be shared without finger pointing. 


\section{Summary}

This document described the methodology and techniques used by the NRC staff to analyze and ultimately to propose a fundamentally new process for materials licensing. An overview of the required elements for large-scale change was described. A brief discussion of the team's analysis methodology, associated findings and potential consequences, and redesign ideas followed. A brief overview of how the team used best practices was presented. The licensing process baseline measures were defined and the NMSS licensing vision was presented. The best practice visits, which enabled the team to creatively expand their vision beyond current practice, were provided. Finally, the major changes required to successfully implement the process were discussed. 


\title{
Appendix A
}

\author{
Materials Licensing \\ BPR Core Team Project Charter
}


Examine the NRC's current materials licensing process and develop a new materials licensing process design that accomplishes the following

- maintains or raises the level of public safety achieved by the current process

- performs an order of magnitude faster than the current process

- exploits modern information technology as a fundamental part of the new process

- reduces resources to meet 1998-1999 staffing levels

To determine any changes required to implement the above goals, you are authorized to examine all related and supporting processes.

You will look outside of the NRC to understand government and commercial best practices that are similar to materials licensing - applying them as appropriate to both the new materials licensing process design and related and supporting processes change recommendations.

You will determine licensee readiness for change and consider licensee-provided redesign ideas to meet licensees' present and future requirements.

You will use the established governance model to guide your efforts, reporting as required by the model.

This assignment is full-time during the periods of time when the core team meets and takes precedence over all other duty assignments.

At the end of the project, you will report:

- changes to the current materials licensing and related supporting process that can be implemented immediately to achieve dramatic improvements

- a new materials licensing process design that can be implemented (unless regulator and/or legislative changes are needed). 
Appendix B

\section{Conceptual Picture of the Current Materials Licensing Process}


Step 1:

Initial Contact

Step 2:

Submit Application
Step 3:

Administrative

Processing
Step 4:

Fee Processing

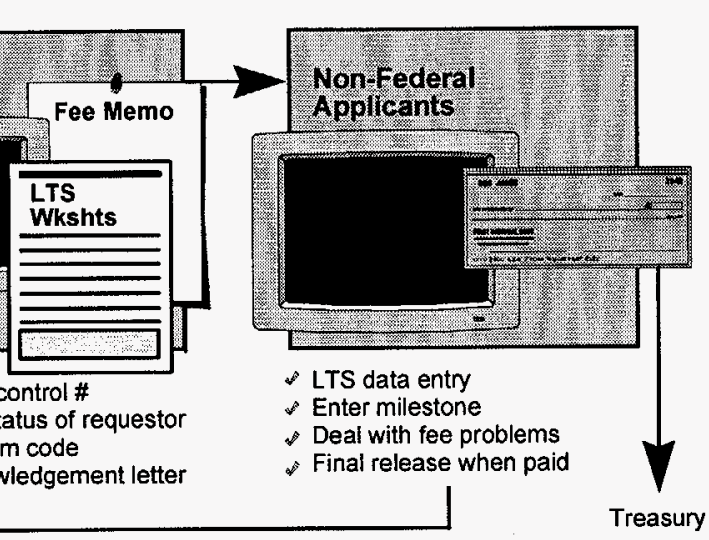

Step 7:

Administrative

Followups

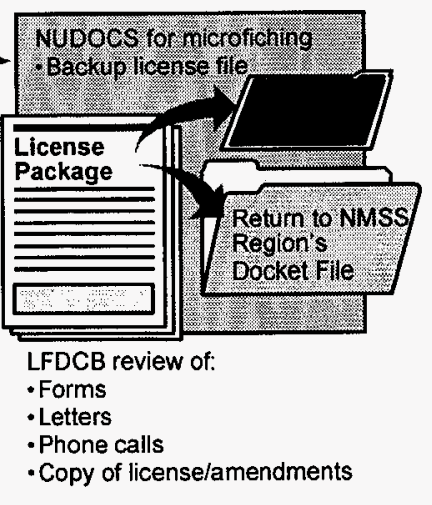

Step 8:

Renewal Reminder

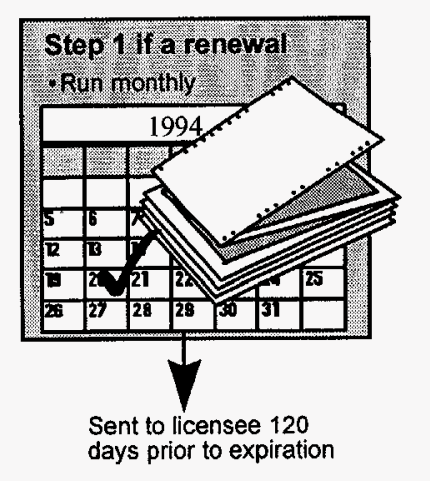




\title{
Appendix C
}

\author{
Actual
}

NMSS Materials Licensing Process 
NMSS Materials Licensing Process Chart

Players and Hand offs

13 January 1995

Step 1 - Initial Contact

Players: 7

Max Interactions: 12

Routine HOs: 5
Step 3 - Administrative Processing

Players: 6

Max Interactions:

Routine HOs: 6
Step 4 - Fee Processing

Players: 10

Max interactions: 16

Moutine HOs: 1

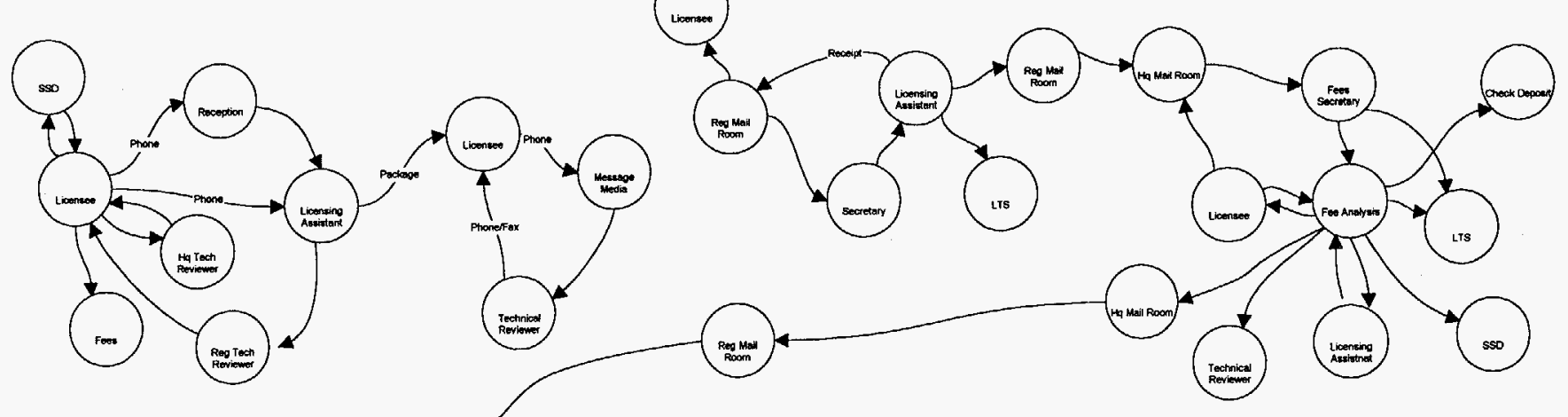

Step 5 - Technical Review

$$
\text { Players: } 6
$$

Max Interactions: 31

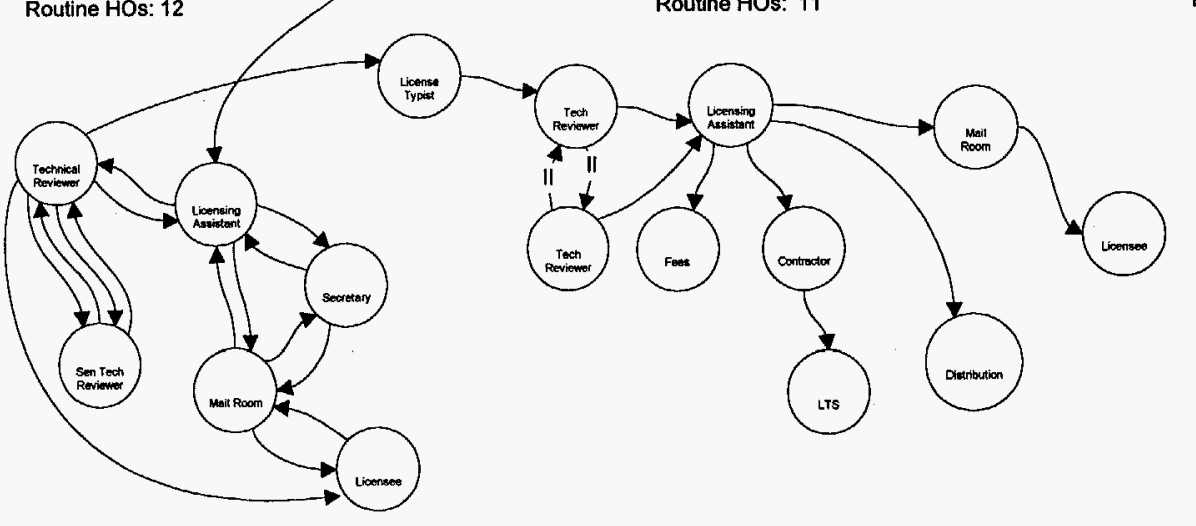

Step 7 - Administrative Followups

Players: 5

Max Interactions: 7
Routine HOs: 7

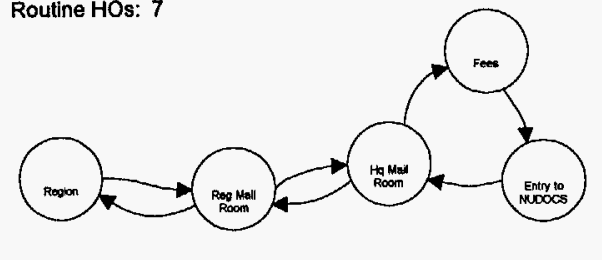

Step 8 - Renowal Reminder

Players: 5

Max Interactions: 5

Routine HOs: 5

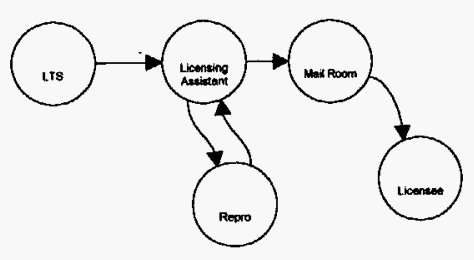




\section{Appendix D}

\section{Current \\ Technical Assistance Request Process}


Tochnical Assistance Request (TAR) Processing Players and Hand offs

13 January 1995

TAR Processing

Players: 18

Max Interactions: 50
Average HOs: 36

Toeniceal

Saction

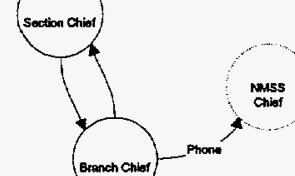

monss

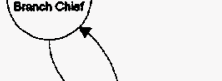

chonsing

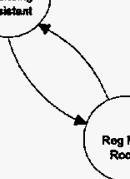
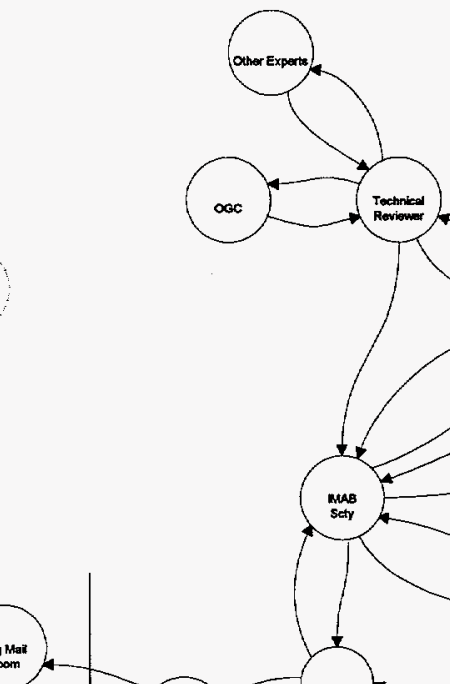

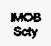




\begin{tabular}{|c|c|}
\hline $\begin{array}{l}\text { U.S. NUCLEAR REGULATORY COMMISSION } \\
\text { BIBLIOGRAPHIC DATA SHEET } \\
\text { (See instructions on the reverse) }\end{array}$ & $\begin{array}{l}\text { 1. REPORT NUMBER } \\
\text { (Assigned by NRC, Add Vol., } \\
\text { Supp., Rev., and Addendum Num- } \\
\text { bers, if any.) } \\
\text { NUREG-1539 }\end{array}$ \\
\hline \multicolumn{2}{|l|}{ 2. TITLE AND SUBTITLE } \\
\hline \multirow[t]{3}{*}{ Methodology and Findings of the NRC's Materials Licensing Process Redesign } & 3. DATE REPORT PUBLISHED \\
\hline & 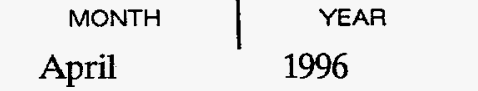 \\
\hline & 4. FIN OR GRANT NUMBER \\
\hline \multirow{2}{*}{$\begin{array}{l}\text { 5. AUTHOR(S) } \\
\text { P. A. Rathbun, K. D. Brown, J. R. Madera, M. Moriarty, } \\
\text { J. M. Pelchat, W. K. Usilton, J. E. Whitten, P. C. Vacca }\end{array}$} & $\begin{array}{l}\text { 6. TYPE OF REPORT } \\
\text { Technical }\end{array}$ \\
\hline & 7. PERIOD COVERED (Inciusive Dates) \\
\hline
\end{tabular}

8. PERFORMING ORGANIZATION - NAME AND ADDRESS (If NRC, provide Division, Office or Region, U.S. Nuclear Regulatory Commission, and mailing address; if contractor, provide name and mailing address.)

Division of Industrial and Medical Nuclear Safety

Office of Nuclear Material Safety and Safeguards

U.S. Nuclear Regulatory Commission

Washington, DC 20555-0001

9. SPONSORING ORGANIZATION - NAME AND ADDRESS (if NRC, type "Same as above"; if contractor, provide NRC Division, Office or Region,

U.S. Nuclear Regulatory Commission, and mailing address.)

Same as 8 . above

10. SUPPLEMENTARY NOTES

11. ABSTRACT (200 words or less)

This report describes the work and vision of the team chartered to redesign the process for licensing users of nuclear materials. The Business Process Redesign team was chartered to improve the speed of the existing licensing process while maintaining or improving public safety and to achieve required resource levels. The report describes the team's methods for acquiring and analyzing information about the existing materials licensing process and the steps necessary to radically change this process to the envisioned future process.

12. KEY WORDS/DESCRIPTORS (List words or phrases that will assist researchers in locating the report.)

\begin{tabular}{l} 
13. AVAILABILITY STATEMENT \\
Unlimited \\
\hline 14. SECURITY CLASSIFICATION \\
\hline (This Page) \\
Unclassified \\
\hline (This Report) \\
Unclassified \\
\hline 15. NUMBER OF PAGES \\
\hline 16. PRICE \\
\hline
\end{tabular}

